\title{
Article \\ Research on Collaborative Order Decision-Making Method for Symmetric Participants in Complex Shipbuilding Projects
}

\author{
Xuezhang Mao ${ }^{1, *}$, Jinghua $\mathrm{Li}^{2, *}$, Boxin Yang ${ }^{2, *}$ and Hui Guo ${ }^{1}$ \\ 1 College of Shipbuilding Engineering, Harbin Engineering University, Harbin 150001, China; \\ hui0625@hrbeu.edu.cn \\ 2 College of Mechanical and Electrical Engineering, Harbin Engineering University, Harbin 150001, China \\ * Correspondence: maoxuezhang@hrbeu.edu.cn (X.M.); lijinghua@hrbeu.edu.cn (J.L.); \\ yangboxin@hrbeu.edu.cn (B.Y.); Tel.: +86-181-4569-2743 (X.M.)
}

Citation: Mao, X.; Li, J.; Yang, B.; Guo, H. Research on Collaborative Order Decision-Making Method for Symmetric Participants in Complex Shipbuilding Projects. Symmetry 2021, 13, 1305. https://doi.org/10.3390/ sym 13071305

Academic Editor: Pecchinenda Anna

Received: 3 June 2021

Accepted: 16 July 2021

Published: 20 July 2021

Publisher's Note: MDPI stays neutral with regard to jurisdictional claims in published maps and institutional affiliations.

Copyright: (c) 2021 by the authors. Licensee MDPI, Basel, Switzerland. This article is an open access article distributed under the terms and conditions of the Creative Commons Attribution (CC BY) license (https:// creativecommons.org/licenses/by/ $4.0 /)$.

\begin{abstract}
More extensive enterprise cooperation is an effective means to increase the competitiveness of shipbuilding companies in the current distributed manufacturing environment. Most crossenterprise collaborative processes for shipbuilding projects have been widely concerned. However, the symmetry and cooperativity among the order decision-making process is rarely involved. A key issue for decision makers is to balance the interests of each symmetric participant and realize the consistent decision-making for the order. Existing order decision-making methods in the shipbuilding industry are low efficiency. The aim of this paper is to provide an assistant decision-making method to support effective order decision-making and multi-party cooperation for the multi-wining negotiation objectives. To solve this problem, a collaborative order decision-making framework based on decision support system (DSS) and multi-agent system (MAS) theory is presented, simulating the collaborative order decision-making process, and bridging the order decision-making with production scheduling. Then, a multi-stage negotiation method is provided to solve the distributed and symmetric order decision-making problem, and an illustrative example is conducted to demonstrate the effectiveness and rationality of the methods. Finally, an application case using a prototype system will be reported as a result.
\end{abstract}

Keywords: shipbuilding project; cooperative decision-making; symmetric order decision-making; multi-agent; multi-issue negotiation

\section{Introduction}

ETO (Engineering-to-Order production mode) is the most remarkable feature in shipbuilding industry [1]. Affected by the downturn in the international shipping market, the global shipbuilding orders continue to decline, which is putting more pressure on the shipbuilders [2,3]. In the meantime, the manufacturing environment is becoming much more distributed with the rapid development of globalization [4]. In such a market environment, it is an inevitable choice for shipbuilding enterprises to increase the competitiveness for order by more extensive cross-enterprise cooperation.

Most cross-enterprise collaborative processes for shipbuilding projects have been widely concerned [5-11], and we have also studied the shipbuilding projects collaborative planning and symmetric scheduling problem [12]. However, the symmetry and cooperativity among the order decision-making process is rarely involved, which caught our attention. In the distributed manufacturing environment, the order decision-making mode has also undergone significant changes. The order decision-making process generally involve multiple participants in complex shipbuilding projects, as shown in Figure 1. In the order decision-making process, the shipowners submit shipbuilding orders to the general contractor from time to time according to market demand, and submit sub-orders of the key equipment/system/technology package to the strategic suppliers. The general contractor and strategic suppliers need to decide whether to accept the orders and the 
specific order completion plan according to their own production and construction capacity. In the decision-making process, there is no subordinate relationship between enterprises, and the decision-making process is distributed and symmetrical. All these geographically distributed cooperative enterprises have their own local goals and make corresponding distributed decisions around the decision-making issues in the process of project, which leads to cross-organization order collaborative decision-making problem between the symmetric participants in complex shipbuilding projects.

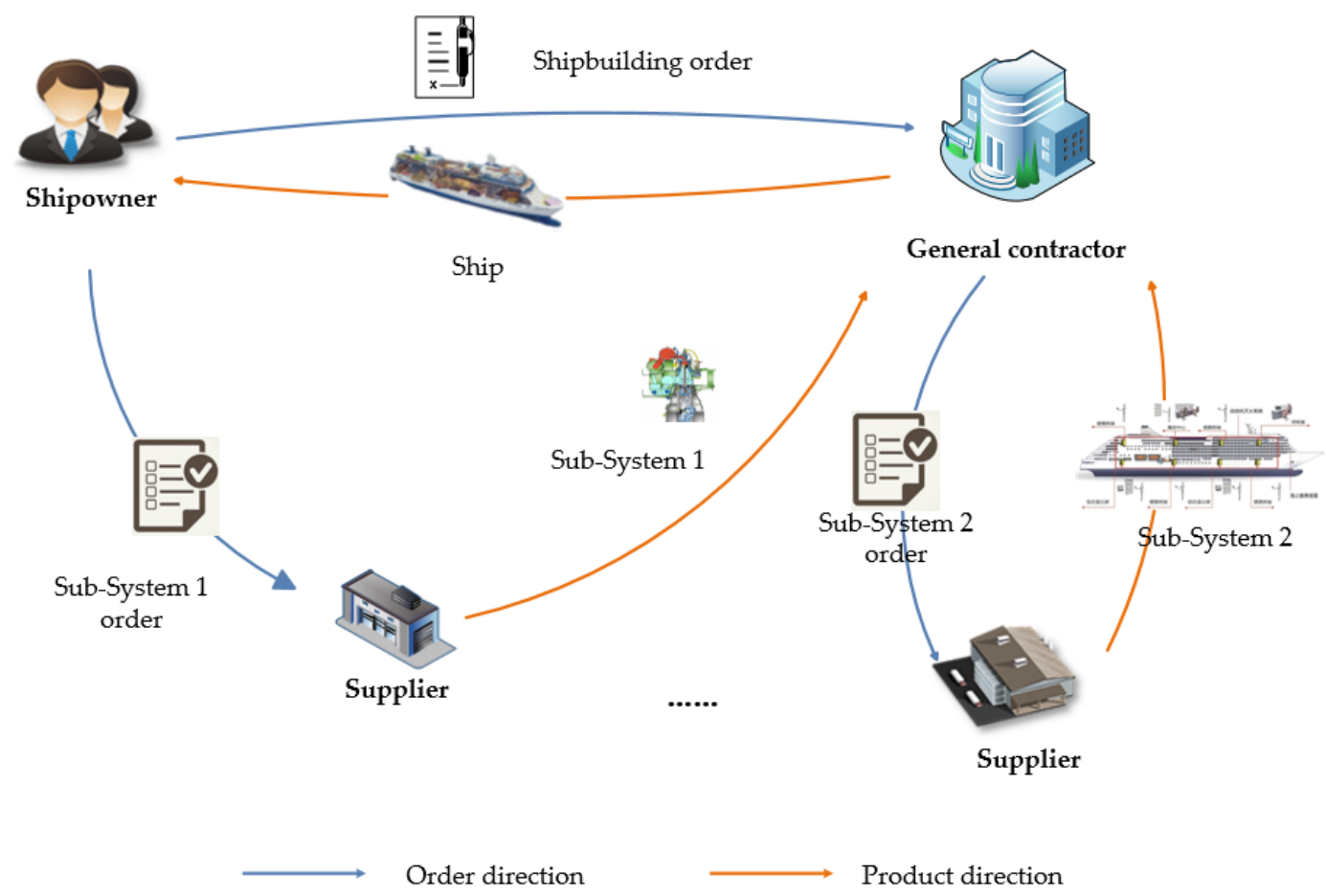

Figure 1. Order decision-making process in complex shipbuilding project.

In the decision-making process, regarding the orders, the shipowner, general contractor and strategic suppliers make multi-party collaborative decisions around shipbuilding orders to determine the order price, delivery date, quality requirements, key construction nodes and other contents. All participants have their own decision objectives.

(1) The shipowner makes partial decisions such as order cost optimization and delivery date optimization according to their own interests, and transmits the expected order price, delivery date, quality requirements and other information to the cooperative production enterprises to realize the manufacturing entrustment of the ship products.

(2) General contractor has the most core resources of shipbuilding. The decisionmaking process needs to consider the overall revenue of orders, whether they can deliver them on time, etc., and also consider the overall scheduling of global manufacturing resources in the multi project parallel shipbuilding mode to determine whether to accept the order and make the key nodes of each order project.

(3) Strategic suppliers provide key equipment/systems/units/technical packages for ship manufacturing [6]. The completion and arrival time of these key equipment/systems/ units/technical packages directly affect the ship construction nodes. In the decision-making process, the strategic suppliers also make local decisions based on their own interests.

The market competition environment determines that the owner, the general contractor and the strategic supplier must take the distributed independent decision-making mode. Because the decision objectives are usually conflicting in the distributed and symmetrical decision-making process, how to balance the interests of each decision-making body and realize the consistent decision-making for the order is the key to the project control in this stage. 
On the one hand, the market competition environment leads to the owner, the general contractor and the strategic supplier must take the distributed independent decisionmaking way, and keep their own private information about capacity and benefit. On the other hand, one enterprise cannot complete all production tasks independently, thus must disclose some information to coordinate with cooperative enterprises. In the process of local decision-making, each subject is multi-objective (such as delivery date, price, quality standard) to optimize decision-making. However, each participating subject has the approximate optimal "public consultation area" for multiple issues, which provides negotiation space for cross-organization collaborative decision-making. Because of the mutual restriction between multiple issues, each participating subject needs to compromise in the process of multi-issue and multi-objective negotiation. In the enterprise planning cycle, the dynamic of candidate orders and the unknown of potential orders also challenge the decision-making. Therefore, it is necessary to study the collaborative order decisionmaking method of complex shipbuilding project under uncertain environment, so as to obtain the multi-wining negotiation results.

However, most previous research on order decision-making problems is from the perspective of single decision-making subject [13-15], ignoring the cross-enterprise proactive collaboration between multiple symmetric decision-making subjects. What is more, existing studies on the shipbuilding order decision-making problem shed little light on the relationship between order decision-making and production scheduling $[9,10]$, which causes extensive engineering changes due to the order decision-making process being out of touch with production scheduling. These models are difficult to meet the order decisionmaking requirements of complex shipbuilding projects. Many studies use symmetric decision-making theory to deal with distributed and symmetrical problems, including the decision-making model [16-20] and decision-making system modeling [21-26]. The purpose of this paper is to provide effective order decision-making methods and an effective decision support system (DSS) for project participants. Multi-agent system (MAS) theory has been proven effective to deal with the distributed decision-making problem [27,28]. The agents following a certain protocol are used to represent logical or physical resources in the decision-making process to achieve the decision-making objectives.

The aim of the research is to provide an assistant decision-making method to support effective order decision-making for the multi-winning negotiation objectives. A collaborative order decision-making framework based on DSS and MAS theory is presented, simulating the collaborative decision-making process, and bridging the order decision-making with the production scheduling. A multi-stage negotiation method is further provided to solve the distributed and symmetric decision-making problem. From the academic perspective, this research is further improved the collaborative and symmetric decision-making theory in complex shipbuilding projects on the basis of previous studies [12].

The rest of the paper is organized as follows: Section 2 reviews the related literature on the order decision-making problem. Section 3 analyzes the characteristics of distributed optimization and collaborative decision-making of complex shipbuilding project order decision-making problem and proposes the problem solving strategy based on phased negotiation. Section 4 gives a multi-agent based symmetric order decision-making system, among which a relaxation based multi-stage negotiation method between the symmetric participants are established. Section 5 provides an experiment and analysis of the proposed approach. Finally, an application case using a prototype system will be reported as a result.

\section{Literature Review}

Research on shipbuilding order decision-making is rarely involved, generally considered that the decision objectives are usually conflicting and it is difficult to realize the collaborative decision-making between the symmetric participants. Therefore, the necessity of order collaborative decision-making is ignored. The research of general order decisionmaking problem and order decision-making considering production scheduling will be 
reviewed firstly. Then, the research of symmetric decision-making is further summarized to obtain the direction of this research.

\subsection{General Order Decision-Making Problem}

The earliest research on order decision-making can be traced back to the server queuing problem for multiple customer categories studied by Miller et al., which can maximize the expected value of the reward in an infinite planning period by studying accepting or rejecting customers [29]. In the follow-up research, the research of order decision-making is gradually extended to the field of acceptance and rejection of manufacturing orders, among which limited manufacturing resources is the most concerned study. Matsui et al. [30,31] considered the resource constraints of the enterprise, assumed that the order could be postponed indefinitely and the time of the order starting production obeyed exponential distribution. They studied the relationship between the order revenue and the processing time of the order, and made the order decision to maximize the revenue. Slotnick et al. [32] studied the problem of selecting partial orders from the known batch order tasks to obtain the maximum order revenue. Lewis et al. [33] studied the application of dynamic programming method in order selection problem to obtain the maximum order revenue.

In the actual order decision-making process, the delivery date of the order is also an important factor. Baker et al. [34] considered the order decision problem with the minimum delivery time and average lead time. Bertrand [35] studied the order decision problem with strict due date constraint and minimum cost. Liao [36] and Balakrishan [37] studied the order decision problem with revenue maximization under strict due date constraints. Keskinocak et al. [38] studied and analyzed two models (the basic model of single customer type and the enhanced model that needs to provide service or production immediately) for coordinating scheduling and due date quotation, introduced the method of immediate reference case, conducted in-depth analysis of the problem and provided a qualitative explanation. Susan et al. [39] studied the decision-making problem of the delivery date of an order with limited production capacity when customers get a discount due to late delivery, but early delivery is neither punished nor rewarded. Zhang et al. [40] studied the order decision-making problem of MTO (make to order) enterprises considering the constraints of production capacity. Through an integer programming model, the order selection, delivery time and production plan were integrated; the maximum profit was taken as the objective to make the order decision. Charnsirosakskul et al. [41] studied the order decision-making problem that manufacturers set prices to influence demand, reject orders and set delivery dates for orders. The proposed decision-making model integrates pricing and production decisions. Song et al. [42] set the overall profit of the supply chain as the goal, considered the order decision-making problem under strict order delivery time and capacity constraints, and established an integer programming model.

\subsection{Order Decision-Making Considering Production Scheduling}

With the deepening research, the order decision-making problem and production scheduling problem are linked together. Ebben et al. [43] studied the problem of integrating order decision-making and resource capacity loading when the order demand exceeds the production load, and proposed complex methods considering technical constraints, such as priority relationship, order release date and due date, to realize the optimization of equipment performance. Yang et al. [13] studied the single machine job order scheduling problem under the condition of fixed job delay cost and reduced processing time, and designed the corresponding algorithm to maximize the final enterprise profit. Chen et al. [14] proposed a hybrid evolutionary algorithm combining genetic algorithm and extreme optimization to improve the scheduling quality and efficiency for the manufacturing production scheduling decision-making problem (selecting orders for processing and determining the optimal production order under multiple constraints). Xiao et al. [44] extended the single node problem to a more complex multi node problem, and considered the situation of multiple 
production lines, established the corresponding order decision model, and designed the simulated annealing algorithm based on multi-dimensional alternating optimization to optimize the order selection and task scheduling problems at the same time. Zhu et al. [45] studied the coordination decision problem of order and delivery time of multiple assembly lines, established the cost model of order scheduling for electronic products, and proposed the assembly simulation scheduling method under the condition of multiple assembly lines, so that enterprises can obtain greater benefits and meet the delivery time requirements of important customers. Wang et al. [46] studied the order decision-making problem with multiple processing nodes and considering the storage cost and delay cost of finished products in advance, established the order decision-making model with flexible due date, and designed an improved particle swarm optimization algorithm to solve the order scheduling problem. Su et al. [15] studied the multi-objective order decision-making and scheduling problem, proposed a two-stage learning optimization system, and used genetic programming to evolve a group of reusable scheduling rules to achieve the scheduling optimization objectives. Fang [47] coordinated order selection and scheduling decision-making from the perspective of supply chain management, and solved the integration problem of order selection and scheduling through improved ant colony algorithm. Xie et al. [48] considered the order acceptance and processing scheduling optimization decision problem with different types of order processing switching time. Yan [49] studied the job shop scheduling problem of order oriented mixed model production line. Aiming at the punctuality of order due date and the simultaneity of parts completion, an improved social particle swarm optimization algorithm based on the double-layer coding mode of process and work piece was proposed. Shen et al. [50] studied the order scheduling problem of multiple workshops with different demands, proposed a multi-level scheduling model including four different workshop orders and production scheduling demands, and designed an enhanced culture gene algorithm based on improved mutation operator to solve the problem. Zhu et al. [51] studied the order decision-making and production scheduling problem with limited production capacity and fixed delivery time under the background of decentralized decision-making with incomplete information, and designed a multi round price raising auction mechanism to maximize the global revenue.

Researchers have also conducted relevant research on order decision-making in more complex uncertain environment. Hao et al. [52] proposed an uncertain order acceptance method based on average reward reinforcement learning. In order to maximize the average expected revenue, a multi-level pricing mechanism is designed, and the different combinations of order type, price and delivery time are taken as the criteria of system state classification. Fan et al. [53] studied the order pricing and acceptance strategy of MTO enterprises based on revenue management, and established a dynamic programming model based on the principle of maximum expected profit. Pei [54] studied the joint dynamic scheduling decision problem of flow shop production and maintenance under uncertain orders, and designed a two-stage pre reaction hybrid robust scheduling strategy. Wang et al. [55] studied the joint decision-making problem of order acceptance and unrelated parallel machine scheduling. Considering the installation time of sequence and machine dependence and the limitation of available machines, the list rejection method and order rejection rule were proposed, and the coevolutionary genetic algorithm was designed to achieve the optimization objective of minimizing the total cost.

By comprehensively analyzing of the above research, we can find that the existing research is to connect the order to the enterprise production line table and make decisions according to the enterprise's own goals, while the collaborative decision-making of the order only involves customers and production enterprises. The order negotiation process of complex shipbuilding project involves shipowners, general contractors and strategic suppliers, which needs multi-party collaborative decision-making. The existing research results provide ideas in the decision-making objective model, but the decision-making methods cannot meet the demand of order decision-making of complex shipbuilding project. 


\subsection{Symmetric Decision-Making}

It is important to find an appropriate decision-making method and tools to help participants make better decisions for the distributed and symmetrical the shipbuilding project order decision process. Symmetric decision-making theory has been widely studied, among which the research of the decision-making model is the most mature. Du et al. studied applying the robust optimization method to the P-center facility location problem under uncertainty and using Gurobi to solve the equivalent robust model [16]. Liu et al. established a security comparison protocol based on the additive secret sharing technology through the cloud model to achieve efficient decision evaluation, which provided an efficient privacy protection decision tree evaluation service for resource constrained customers [17]. Zeng et al. developed a spherical fuzzy rough set model hybrid with TOPSIS (technique for order preference by similarity to ideal solution) based comprehensive model to help multi-attribute human opinions decision-making [18]. Kucharska considered the dynamic appearance of customers to serve during the design or execution of the routes and proposed a classification of the dynamic vehicle routing problem (DVRP) [19].

These studies are usually considering multiple standards or perspectives and building a multi-standard decision-making (MCDM) framework. The most popular methods include PROMETHEE (preferred order structure assessment method), TOPSIS, AHP (analytic hierarchy process), DEMATEL (decision-making and trial evaluation laboratory), VIKOR (Višekriterijumsko kompromisno rangiranje), ANP (analytic network process), ARAS (additive ratio assessment), WASPAS (weighted aggregated sum-product assessment) and COPRAS (complex proportional assessment) [20].

Other researchers focus on modeling business process and decision-making process. Jeong et al. provided an efficient-parallel processing framework with only a one-time parallelized full scan for the collaborative filtering method, which adhere to the sequential access patterns on Hadoop data nodes [21]. Kim et al. studied a load-balancing scheme for processing large-scale jobs using mobile resources without a cloud server (adaptive mobile resource offloading, AMRO), which is applied in a mobile cloud computing environment based on collaborative architecture [22]. Machuca et al. developed a 3D mobile interaction technique, allowing users to create a symmetric and collaborative ambience and collaborate with other people [23]. Wu et al. provided a collaborative and synchronization computer aided design (Co-CAD) method to achieve that all Co-CAD sites maintain symmetric and consistent operating procedures [24]. Dursun et al. developed an integrated decisionmaking framework for material selection procedure [25]. Yang et al. presented an agentbased decision-making system, simulating the deep foundation pit evacuation under the situation of the presence of collapse disaster [26].

\subsection{Conclusions on the Reviewed Literature}

The existing research on project order decision-making mainly focuses on local decision-making methods, and only focuses on the cooperation mode of both parties in terms of cooperation objects. There is no research on the related problems from the perspective of symmetric decision-making. The cross-organization order collaborative decision-making of complex shipbuilding project is a multi-agent, multi-issue and multiobjective collaborative decision-making process for ship orders based on distributed local decision-making of general contractor, ship owner and strategic supplier. The market competition environment determines that the owner, the general contractor and the strategic supplier must take the distributed independent decision-making mode. Because the decision objectives are usually conflicting in the distributed and symmetrical decisionmaking process, how to balance the interests of each decision-making body and realize the consistent decision-making for the order is the key to the project control in this stage. The existing research provides ideas for collaborative decision-making model. However, considering the background, object, goal and complexity of the order decision-making problem, the multi-party collaborative decision-making method and negotiation mechanism for complex shipbuilding project orders need to be further studied. 
In order to achieve the multi-win result of order decision-making, the following two aspects of work needs to complete: (1) Deeply analyze the partial and coordination process of shipbuilding order decision-making to find the relationship between local decision making and global coordination. (2) Based on the existing research results, this paper seeks for a suitable method to build a symmetric and coordinated order decision framework, and designs a negotiation method to achieve the goal of multiple symmetric participants collaborative decision.

\section{The Collaborative and Symmetric Order Decision-Making Process in Shipbuilding Projects}

\subsection{Order Collaborative Decision-Making Process}

\subsubsection{Order Oriented Enterprise Collaboration}

Based on the characteristics of complex shipbuilding projects, the general contractor needs to obtain orders through enterprise cooperation. By giving full play to the advantages of enterprise cooperation, the rapid response to orders can be realized, and more order carrying capacity can be obtained with a more reasonable manufacturing scheme. Different order tasks lead to different roles of cooperative enterprises. Through enterprise cooperation, we can realize the complementary advantages of resources, maximize the utilization of resources, improve shipbuilding efficiency, reduce shipbuilding cost and realize the rapid response to shipbuilding orders. The cooperative enterprise alliance is formed according to the increase of order demand, and also disintegrates with the decrease of order demand. The structure of enterprise cooperation changes dynamically with shipbuilding orders and projects [6], as shown in Figure 2.

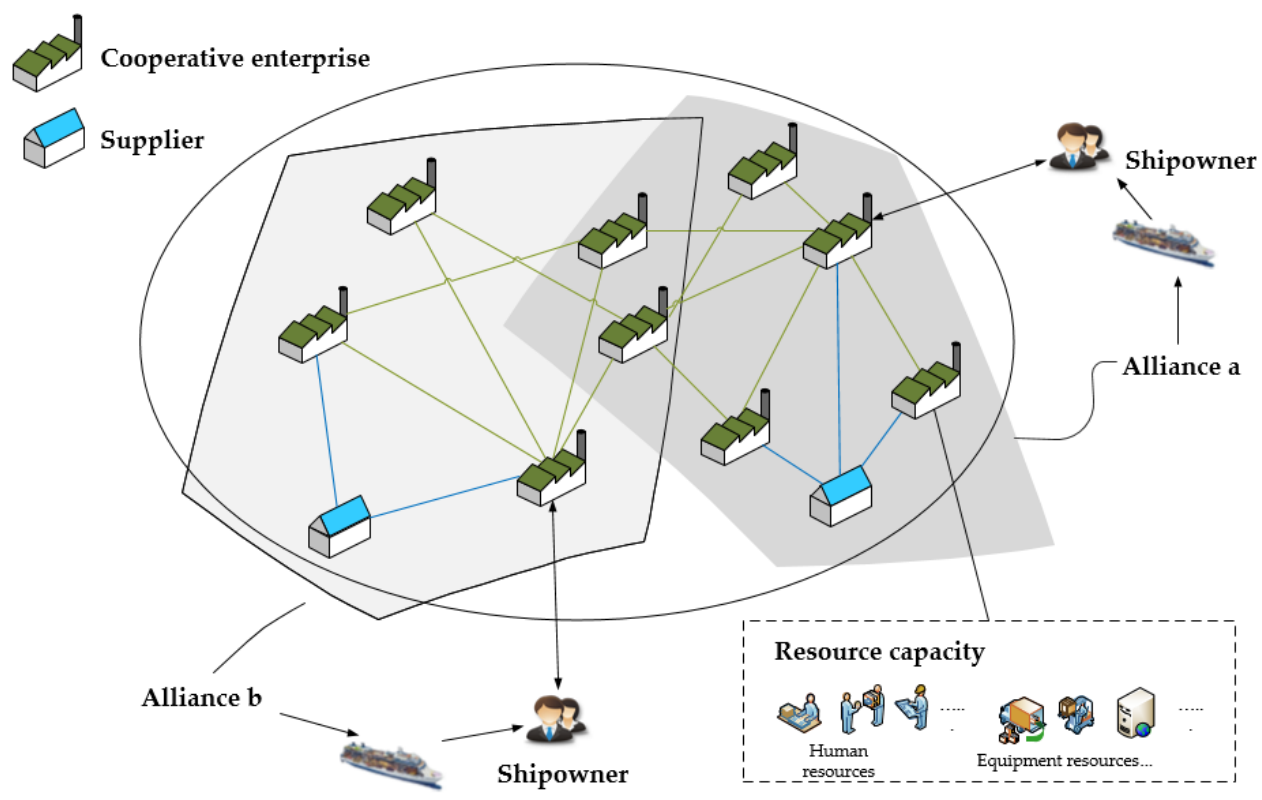

Figure 2. Order oriented enterprise collaboration.

\subsubsection{Cooperative-Game Decision-Making Process}

Shipowners generate shipbuilding demand from time to time according to market demand, and submit shipbuilding orders to the general contractor. Meanwhile, they send multiple sub-orders of key equipment/system/technology package to the intended strategic suppliers. The general contractor and strategic supplier need to decide whether to accept the order according to their own production capacity. If the order is accepted, the supplier needs to produce or provide key equipment/system/technology to the general contractor, who will complete the final product and deliver it to the ship owner.

According to the submission time of each candidate order $k$, the enterprise planning cycle $T$ is divided into $N$ stages, that is, when each candidate order is submitted, a new 
stage is started, and then the order decision of one stage and the overall decision of multiple stages in the whole planning cycle are concerned, respectively. The staged dynamic order decision based on order submission time is shown in Figure 3.

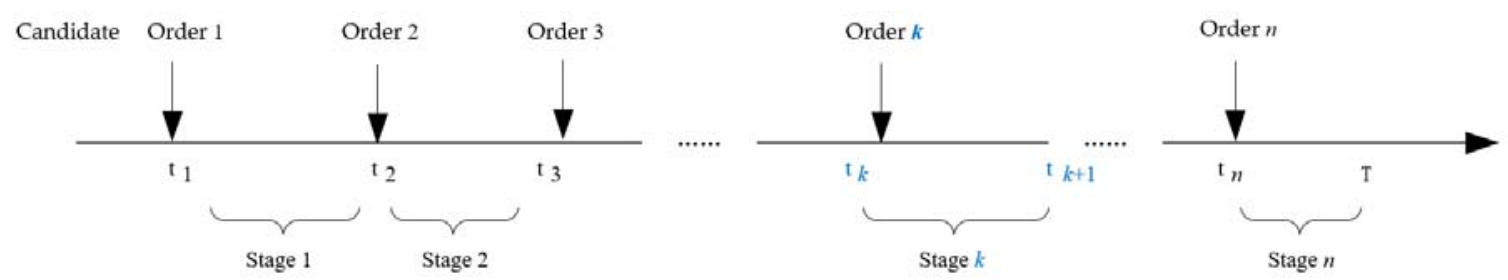

Figure 3. Candidate order decision-making interval.

When the candidate order $k$ is submitted to the enterprise, the enterprise needs to decide whether to accept the order. Suppose that the start time of $k$ phase is $t_{k}$, according to the availability of resources at this time $x_{k}$ (corresponding period $\left[t_{k}, T\right]$ ) to decide whether to accept the order. In this case, besides $x_{k}$, the known information also includes the release date $r_{k}$, delivery date $d_{k}$ and time baseline $\overline{d_{k}}$ of order $k$, also the maximum expected return $P_{k}$ and tardiness penalty function $R_{k}=f\left(P_{k}, d_{k}, \overline{d_{k}}\right.$, plan $)$.

Whether an enterprise accepts the order or not, it needs to consider its own resources and the production plan of other projects, and allocate resources according to the project income. According to the order demand, the general contractor needs to make a preliminary project plan, determine the construction nodes of the project and the cooperation time nodes of key equipment/tasks, as shown in Figure 4.

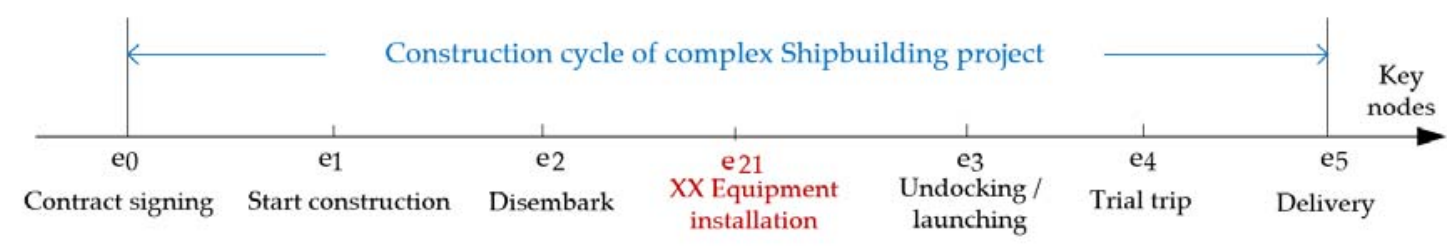

Figure 4. Preliminary project plan.

Complex shipbuilding project resources include fixed resource $R^{f}$ and renewable resource $R^{r}$. The feasible project scheme needs to meet the conditions that fixed resources and renewable resources do not exceed the upper limit of available resources. All feasible schemes constitute the set of feasible schemes $A_{k}=\left\{a_{k^{\prime}}^{1} a_{k^{\prime}}^{2}, \ldots, a_{k^{\prime}}^{j}, \ldots, a_{k}^{J}\right\}$ in phase $k$. Among them, the scheme $a_{k}^{j}=\left(a_{k R^{f}}^{j}, a_{k R^{r}}^{j}, a_{k S}^{j}\right), a_{k R^{f}}^{j}$ indicates the resource allocation scheme and key supply scheme corresponding to the scheme, $a_{k R^{r}}^{j}$ represents the allocation of renewable resources, $a_{k S}^{j}$ indicates the supply requirements of key equipment, $a_{k S}^{j}=\left\{d_{k S}^{j}, p_{k S}^{j}, q_{k S}^{j}\right\}$ represent the arrival time, purchase price and equipment quality requirements of the required equipment, respectively.

The cooperative enterprises of complex shipbuilding project belong to the typical cooperative game relationship. Participating enterprises need to cooperate with each other to achieve the overall goal of the project; at the same time, the allocation process of task and project income is also a game process between cooperative enterprises. The general contractor cooperates with shipowners and strategic suppliers on the basis of distributed local decision-making to determine the scheduling of key nodes and key manufacturing resources. In this stage, shipowners, general contractors and strategic suppliers make collaborative decisions around shipbuilding orders to determine the order price, delivery date, quality requirements and key construction nodes, as shown in Figure 5. 


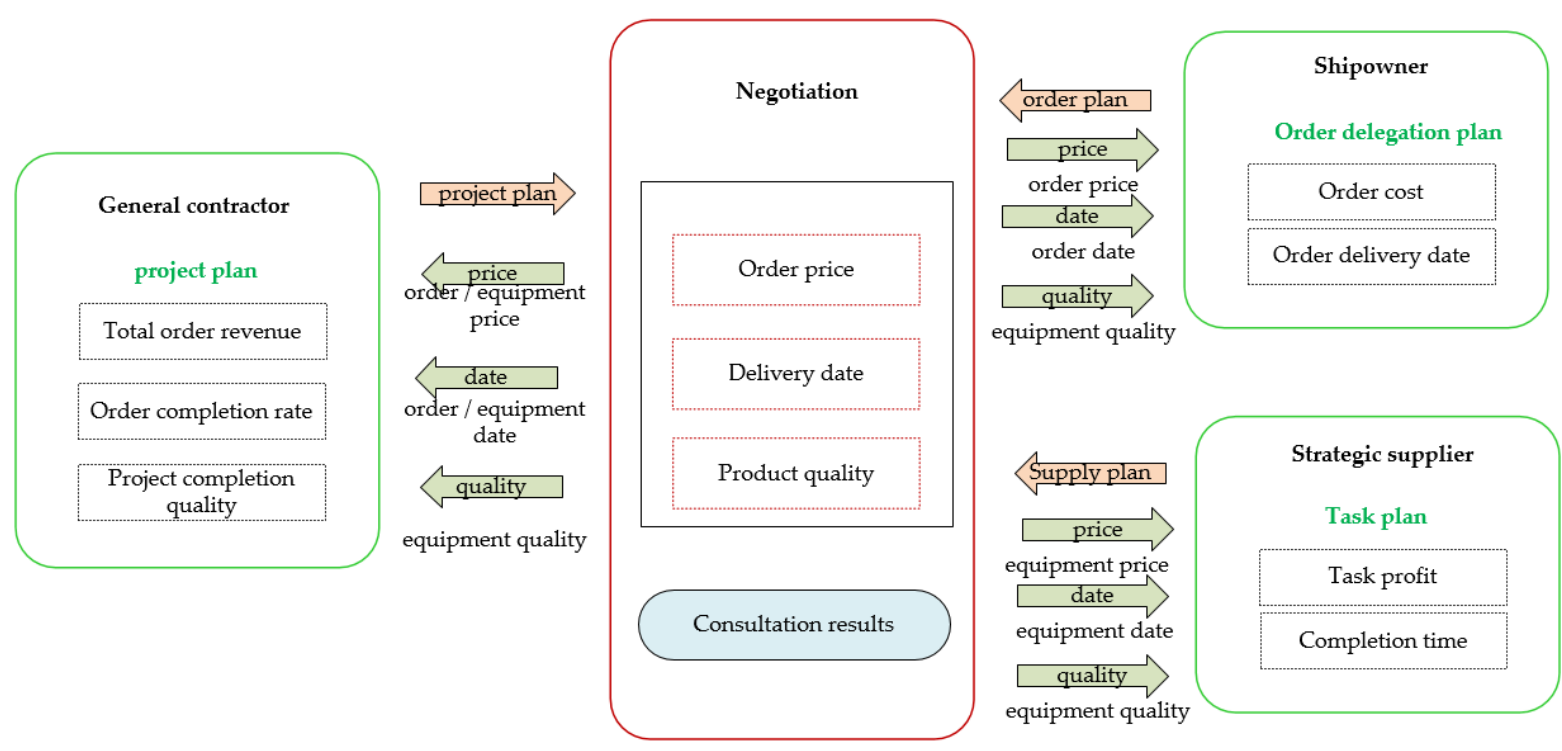

Figure 5. Collaborative order decision-making in complex shipbuilding project.

In the process of order decision-making, participants have their own decision-making objectives.

(1) Ship owners make local decisions such as order cost optimization and delivery date optimization according to their own interests, and transfer the expected order price, delivery date, quality requirements and other information to the cooperative production enterprises, so as to realize the manufacturing entrustment of ship products.

(2) General contractors have the most core resources of shipbuilding. The decisionmaking process needs to consider the overall revenue of the order, whether it can be delivered on time and other factors, as well as the overall scheduling of manufacturing resources under the multi project parallel shipbuilding mode, so as to determine whether to accept the order and make the key nodes of each order project.

(3) Strategic suppliers provide key equipment/systems/units/technology packages for shipbuilding. The completion and arrival time of these key equipment/systems/units/ technology packages directly affects the shipbuilding nodes. In the decision-making process, strategic suppliers should also make local decisions based on their own interests.

\subsubsection{Decision Model and Notation (DMN) Based Decision-Making Process}

The market competition environment determines that shipowners, general contractors and strategic suppliers must adopt the mode of distributed independent decisionmaking, and because the decision-making objectives are usually conflicting with each other, how to balance the interests of decision-makers and realize the consistent decisionmaking for orders become the key to project regulation in this stage. By describing the distributed decision-making process with decision model and notation (DMN), the whole order decision-making process and bases can be understood more clearly. The DMN-based decision-making process is shown in Figure 6.

Different from the traditional way of receiving orders for ship projects, obtaining orders through collaborative decision-making needs to solve the problem of participants' benefit distribution and ability cooperation, and the collaborative decision-making model that makes participants satisfied is the key. At the same time, considering the success rate of order negotiation and maximizing the interests of cooperative enterprises, it is necessary to study the collaborative decision-making method for complex shipbuilding project orders, so as to improve the ability of rapid response to orders. 


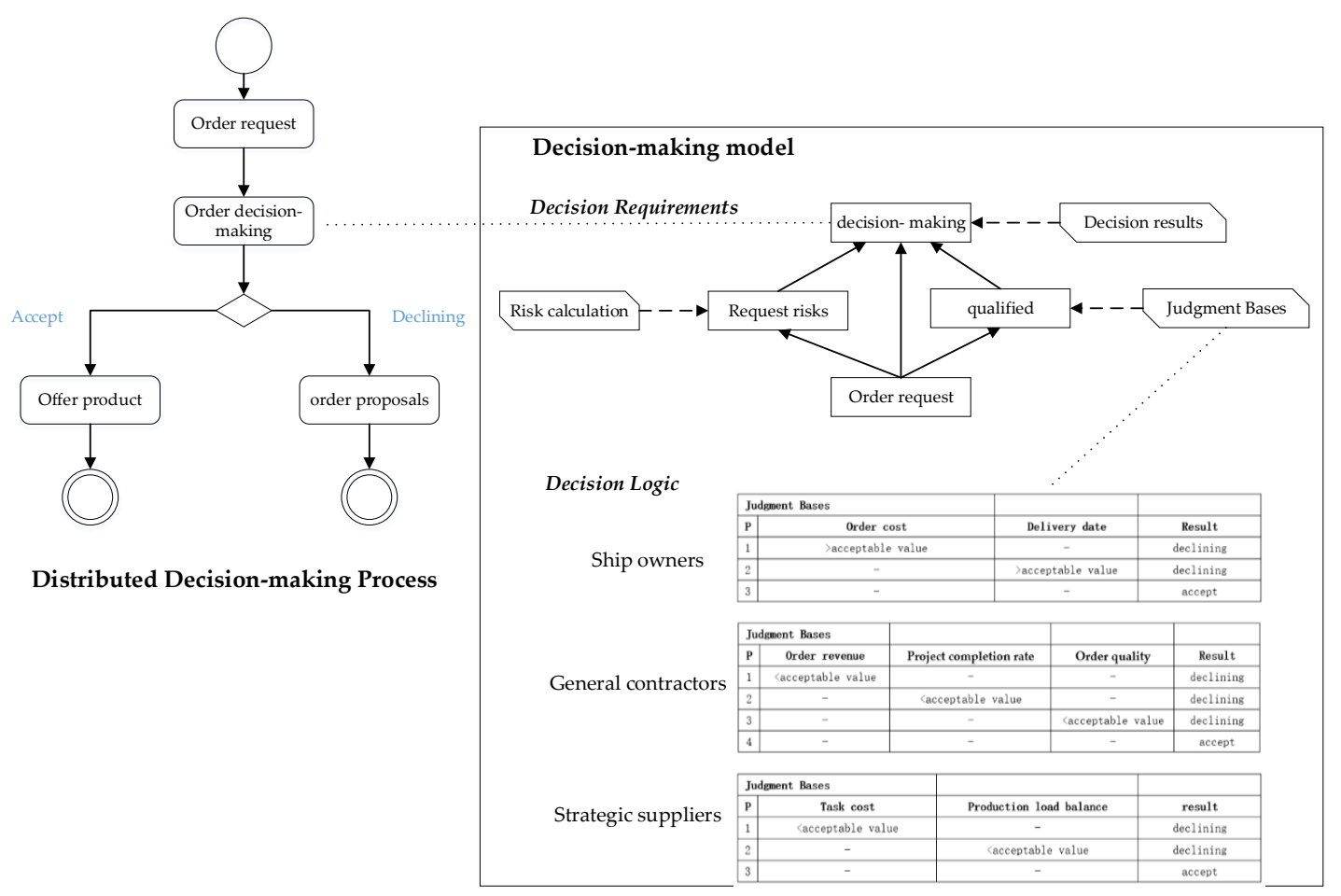

Figure 6. DMN-based decision-making process.

\subsection{Symmetric Decision-Making Process}

From the above order decision-making process, it can be seen that shipowners, general contractors and strategic suppliers carry out distributed multi-objective scheduling optimization around orders, and then make relevant multi-issue information public for coordination. When there is a negotiation gap, each subject makes certain compromises and concessions, adjusts the issue value and iterates until the negotiation succeeds or fails. Complex shipbuilding project order decision-making is a multi-party collaborative decision-making process based on distributed and symmetric local decision-making by the general contractor, shipowners and strategic suppliers.

Different from the traditional order decision-making problem, the order collaborative decision-making problem of complex shipbuilding project has the characteristics of distributed decision-making, multi-agent collaboration (shipowner, general contractor, strategic supplier), uncertain environment (dynamic change of order), multi-objective (local multi-objective scheduling optimization), multi-issue (order price/delivery time/quality) negotiation, etc. This is a multi-subject, multi-objective and multi-issue distributed order collaborative decision-making problem in uncertain environment. When there is an approximately optimal "public negotiation domain" that can be accepted by each subject for multiple issues with different goals, there is room for negotiation and the possibility of reaching agreement in cross organizational collaborative decision-making. Due to the mutual restriction between multiple issues, it is also necessary to compromise in the process of multi-agent and multi-issue negotiation, so as to obtain a consensus result.

\subsection{Problem Analysis and Solution Strategy}

\subsubsection{Collaborative Order Decision-Making Problem}

The order decision-making problem of a complex shipbuilding project is a typical project scheduling problem with multi-subject cooperation and multi-issue linkage. The goal of order collaborative decision-making is to achieve multi-subject multi-issue negotiation under the constraint of public acceptable negotiation domain, and the results are close to the optimization goal. However, the solutions obtained by multi-subject independent optimization are difficult to intersect quickly, the main reasons are as follows: 
(1) In the distributed decision-making environment, multi-subject coordination decisionmaking is difficult. It is necessary to transform "multi-subject multi-objective problem" of decision-making agent into "multi-subject negotiation problem of multi-subject multiobjective problem of single subject", which focuses on the modeling of local decisionmaking and distributed coordinated decision-making of single decision-making agent.

(2) In local decision-making environment, multi-objective decision-making is highly coupled. It is necessary to decompose multiple objective functions to transform "single subject multi-objective problem" into "multiple single objective problems multi-issue adjustment problem". The key point of this process is the adjustment of linkage multi-issue.

Through the decomposition and analysis of the problem, it is concluded that the key to solve the problem is how to integrate the whole solving process and realize the organic unity of local optimization and distributed coordination. In order to solve the original problem (multi-subject multi-objective optimization problem), we need to focus on the multi-subject distributed coordination decision-making method.

Due to the different types of enterprises participating in the order decision-making of complex shipbuilding project, and the decision-making objectives are also different, the local decision-making is faced with multi-objective optimization problems. Although the Pareto solutions can be obtained by the approximate algorithm, the decision-makers interact with each other on multiple issues. Therefore, it is difficult to obtain the multi-subject simultaneous convergence of Pareto front. In order to solve this problem, we can transform the multi-objective optimization problem into multiple single objective optimization and coordination problems, and then seek the result of simultaneous and rapid convergence of multiple issues by means of phased negotiation.

\subsubsection{Salient Features of the Problem}

In order collaborative decision-making process, in addition to the incomplete order information, due to the characteristics of multi-subject distributed collaborative decisionmaking and complex shipbuilding project order decision-making, there are more uncertainties in problem solving, including the dynamics of candidate orders, the uncertainty of potential orders and information unreliability caused by private information reservation.

(1) Dynamics of candidate orders

In the traditional static order decision-making problem, the decision maker is faced with the "static candidate order pool", that is, it needs to "select" some orders from the candidate orders determined by some information for decision-making and production. Enterprises are generally faced with the candidate orders put forward by different shipowners from time to time, forming a "dynamic candidate order flow". Due to the complexity of products and the advance of decision-making, these candidate orders have information integrity. Candidate orders from different shipowners are submitted one by one and irregularly. Enterprises make decisions on whether to accept these candidate orders and reply to shipowners in time. These candidate orders form a "candidate order flow" with strong dynamic characteristics. With the continuous dynamic submission of candidate orders, there are candidate orders in the whole planning cycle. Enterprises need to make timely decisions after receiving each candidate order to determine whether to accept the order or not, and if so, all the project plans and arrangements.

(2) Uncertainty of potential orders

After accepting the current candidate order, the enterprise needs to arrange the production of the products contained in the order and allocate the corresponding resources. On the other hand, the production capacity of the enterprise is limited, so accepting new orders will occupy a certain capacity, which will reduce the ability to accept new orders in the future. No one can accurately predict whether there are candidate orders in the future, let alone the delivery time and product information of these potential orders. However, if such potential orders are not considered in the decision-making process, it will inevitably affect the resource allocation in the whole planning horizon, and ultimately re- 
duce the total revenue of long-term orders. Therefore, the trade-off between current orders, production capacity and future potential orders poses a huge challenge for decision makers.

(3) Information unreliability caused by private information reservation

The market environment determines that it is impossible for shipowners, general contractors and strategic suppliers to disclose all their own information in the process of collaborative production, that is, to retain private information. Multi-subject enterprises only disclose the expected price of the current round of negotiation, whether to accept concession conditions and other information for the negotiation process, and do not disclose their own acceptable negotiation area, ideal price of the issue, expected revenue, final revenue and capacity information. This reservation of private information further increases the unreliability of information in order decision-making process.

To sum up, there are many uncertainties in the collaborative decision-making process of complex shipbuilding project orders, which need to be reasonably solved in the process of modeling and solving, so as to achieve the accuracy, effectiveness and feasibility of decision-making.

\subsubsection{The Strategies of Solving the Problem}

Based on the above analysis, the problem-solving strategies are designed as follows:

(1) Firstly, shipowners, general contractors and strategic suppliers select a goal as the local optimization decision-making goal according to their own preferences. Without considering other influences, the optimal value of each independent decision-making issue and the acceptable negotiation domain are calculated.

(2) Then, the multi-issue optimal values and acceptance negotiation domains of the three parties are summarized to judge whether the optimal values are consistent. If they are consistent, there is no need to negotiate. These optimal values are the target results of order collaborative decision-making. If not, the "public negotiation domain" of multi-subject and multi-issue is calculated to further optimize in this space.

(3) Negotiation concession is carried out for the issues that cannot reach an agreement, that is, each decision-maker carries out iterative negotiation and compromise within the acceptable negotiation domain, until they find the acceptable results of the issues, so as to realize the win-win collaborative decision-making of multi-subject negotiation. If they cannot find, the negotiation will fail and the order will not be accepted.

In this paper, the multi-objective optimization problem is transformed into multiple single objective optimization plus coordination problems. Firstly, the optimal value of each subject's independent decision-making issue is obtained by one objective. When there is a gap, the objective is relaxed, and other objective optimization is carried out, and the issue is compromised and adjusted. The time-consuming of repeatedly solving multi-objective optimization problems and the problem of difficult intersection of multi-subject objective fronts are avoided, it can obtain more multi-subject win-win results in an acceptable time, and achieve the effect of rapid convergence of multiple issues at the same time.

In the whole solution process, there are the following key links:

- Shipowners, general contractors and strategic suppliers search for the optimization results of concerned issues according to their own environment and make local optimization decisions;

- We need to design a coordination mechanism that can effectively solve the multisubject multi-issue negotiation in stages;

- Different from the traditional "trade-off" concession, multi-subject needs to study more appropriate concession strategies due to the linkage of issues;

- Because decision-makers focus on multiple issues that restrict each other, the strategy of issue adjustment needs to consider the balance and priority of multiple issues;

- The dynamic of candidate orders, the unknown of potential orders and other uncertain factors bring the complexity of decision-making solutions. 


\section{Symmetric Collaborative Order Decision-Making System}

\subsection{The System Framework}

In order to mobilize the collaborative initiative of order decision-makers of complex shipbuilding project, the general contractor, shipowner and strategic supplier are regarded as agents with independent beliefs and independent decision-making, and the order collaborative decision-making problem of complex shipbuilding project is solved from the perspective of multi-agent negotiation decision-making. The system is designed for symmetric collaborative decision-making with three types of agents, namely general contractor (GA), shipowner agent (SOA), subcontractor agent (SCA). The proposed system framework is shown in Figure 7.

GA

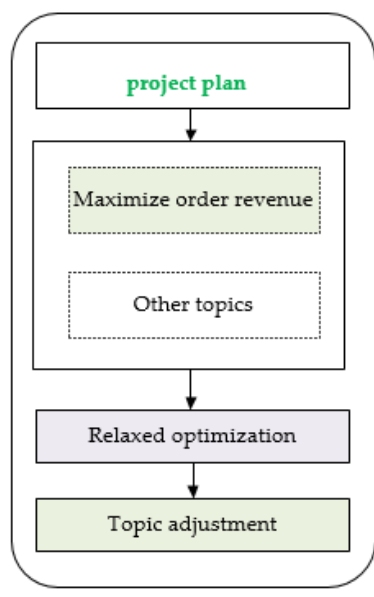

SOA

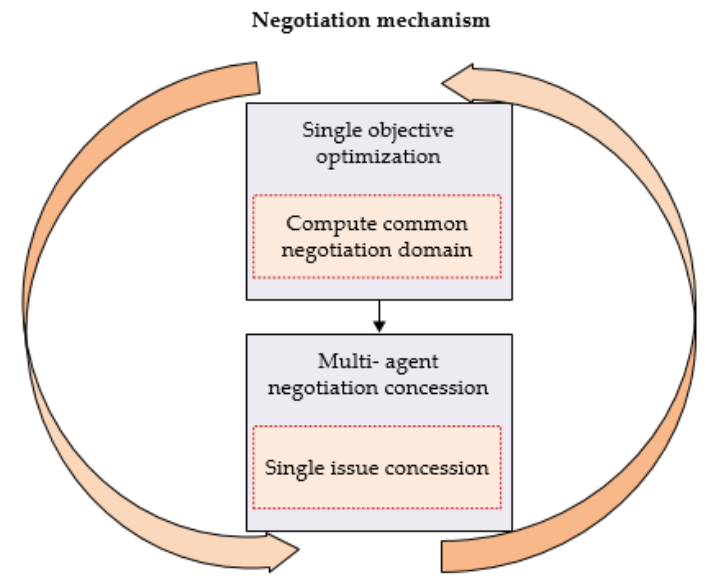

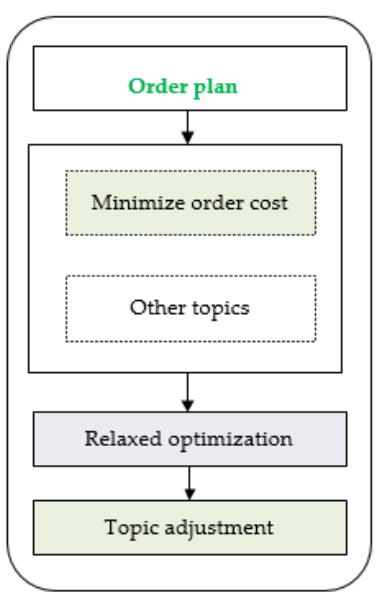

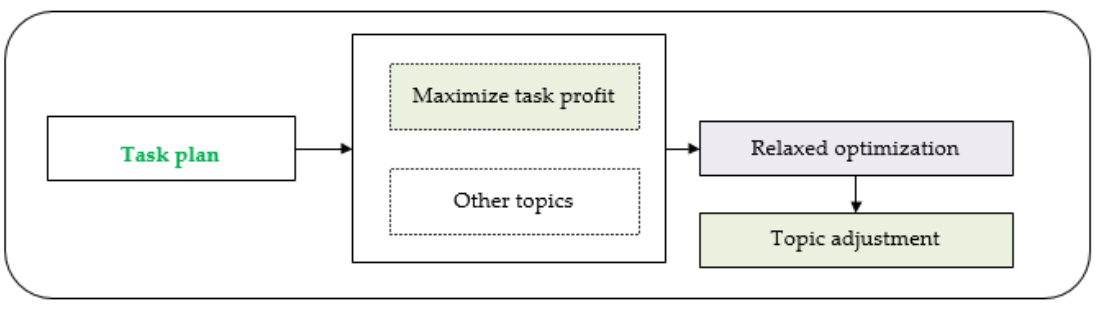

Figure 7. The system framework.

\subsection{Local Decision-Making of Each Agent}

In the local decision-making process, the decision-making objective of SOA is to minimize the order cost and the delivery date under the constraints of quality and deadline. GA needs to consider all possible orders, make node plan for each project, calculate order revenue based on project cost estimation and target profit rate, and consider the completion rate and overall quality target of the order. Based on the quality requirements of equipment/system, SCA make corresponding production plans to achieve the goal of maximizing revenue and balancing production load.

\subsubsection{GA Decision-Making Model}

For the general contractor, the order decision is also the planning and optimization of its own manufacturing capacity. In the planning cycle $\mathrm{T}$ of an enterprise, the decision of every stage $k$ needs to be an optimization decision, so as to achieve the goal of optimization in the whole decision-making process. This is a typical stochastic dynamic programming problem. The capability state of the enterprise at the beginning of phase $k$ is $x_{k} \cdot \varphi$ is seted as state transition function, calculate the state of $k+1$ phase:

$$
x_{k+1}=\varphi\left(x_{k}-a_{k}^{j}\right)
$$


The decision goal of stage $\mathrm{K}$ is to maximize the revenue after accepting order $\mathrm{K}$. The revenue includes the revenue generated by completing order $k$ and the impact on subsequent orders after accepting order $\mathrm{K}$.

$$
f_{k}\left(x_{k}\right)=\left\{\begin{array}{c}
\max _{A_{k}}\left\{g_{k}\left(a_{k}^{j}\right)+E\left[f_{k+1}\left(x_{k+1}\right)\right]\right\}, k \neq n \\
\max _{A_{k}} g_{k}\left(a_{k}^{j}\right), k=n
\end{array}\right.
$$

In the formula, $g_{k}\left(a_{k}^{j}\right)$ denotes the revenue of project plan $a_{k}^{j}$. If not accepting the order, let $j=0$, then $g_{k}=0$, there is no income; otherwise, $g_{k}=P_{k}-R_{k}^{j}-C_{k}^{j}-p_{k S^{\prime}}^{j}$ where $P_{k}$ is the maximum order revenue, $R_{k}^{j}$ is delay penalty, $C_{k}^{j}$ is delay penalty, $p_{k S}^{j}$ is the purchase price of key equipment; and $E\left[f_{k+1}\left(x_{k+1}\right)\right]$ is the expected revenue of the order $\mathrm{k}$ decision to the subsequent order.

In the whole planning cycle of an enterprise, order decision-making needs to select some of the $n$ orders in the dynamic candidate order flow to accept and execute, so as to achieve the goal of maximum actual revenue. At the beginning of stage $k$, when the candidate order $k$ is proposed, the decision maker needs to decide whether to accept the order and how to allocate resources if the order is accepted. Maximize global order revenue:

$$
\max \left\{g_{n}\left(a_{n}^{j}\right)+\sum_{k=1}^{n-1}\left\{g_{k}\left(a_{k}^{j}\right)+E\left[f_{k+1}\left(x_{k+1}\right)\right\}\right\}\right.
$$

In order oriented local decision-making process, the general contractor needs to consider the three optimization objectives of order revenue, completion rate and quality, and carry out project scheduling according to its own resources and the supply situation of strategic suppliers to solve the multi-objective optimization problem. Based on the problemsolving strategy in the previous section, the order oriented local decision-making problem of the general contractor needs to transform the multi-objective scheduling optimization problem into three single objective scheduling optimization problems, coordinate the three single objective scheduling problems, and establish the corresponding objective optimization model and coordination model. The objective models of the three single objective scheduling optimization problems are order revenue optimization model, completion rate optimization model and quality optimization model:

(1) The order revenue optimization model of the general contractor is as follows

$$
Z P 1=\max \left\{g_{n}\left(a_{n}^{j}\right)+\sum_{k=1}^{n-1}\left\{g_{k}\left(a_{k}^{j}\right)+E\left[f_{k+1}\left(x_{k+1}\right)\right\}\right\}\right.
$$

The constraints are:

$$
\begin{gathered}
a_{k}^{j}=\left(a_{k R^{f}}^{j}, a_{k R^{r}}^{j}, a_{k S}^{j}\right) \in A_{k} \\
g_{k}\left(a_{k}^{j}\right)=\left\{\begin{array}{c}
0, i f j=0 \\
p *\left(R_{k}^{j}+C_{k}^{j}+p_{k S}^{j}\right), \text { else }
\end{array}\right. \\
R_{k}^{j}=f\left(P_{k}, d_{k}, \overline{d_{k}}, a_{k}^{j}\right) \\
C_{k}^{j}=C_{k}^{f}+C_{k}^{r} \\
C_{k}^{f}=c^{f} * d_{k} \\
C_{k}^{r}=\sum_{t=s t_{k}}^{f t_{k}} \rho_{t}^{r} * c_{t}^{r}
\end{gathered}
$$

Among them, the objective function (4) indicates that the total revenue of all stages in the enterprise planning cycle is the largest, $g_{k}\left(a_{k}^{j}\right)$ is a decision made for the order $k$ in $k$ phase, and $\left.E\left[f_{k+1}\left(x_{k+1}\right)\right]\right\}$ is the effect of order $k$ on subsequent orders. Formula (5) is the corresponding order decision scheme. Formula (6) is the revenue of order $k, p$ is the target profit rate, that is, the counter quotation of the general contractor for the order is calculated based on the total project cost and target profit. Formula (7) is the penalty 
for late delivery. Formula (8) is the cost of using resources. Formula (9) is the calculation method of fixed resource cost, $c^{f}$ is the unit price of fixed resources. $d_{k}$ is the time spent on resources; Formula (10) is the renewable resource cost calculation method. $\rho_{t}^{r}$ is the number of resources used for time; $r_{t}^{r}$ is the unit price.

(2) Optimization model of project completion rate for general contractor:

$$
Z P 2=\max \sum_{i=1}^{Z}\left(l_{i}^{\text {end }}-l_{i}\right) / z
$$

where $z$ is the number of orders accepted based on local decision, $l_{i}^{e n d}$ is the period corresponding to the order $i$ accepted, $l_{i}$ is the shortest working period without considering resource constraints.

(3) Order quality optimization model of general contractor:

$$
\mathrm{ZP} 3=\max \sum_{i=1}^{Z} \sum_{j=1}^{I} q_{i j} * w_{i j} / z
$$

where $z$ the quantity of orders accepted is based on local decision, $q_{i j}$ is the quality requirement of key equipment $j$ corresponding to order $i ; w_{i j}$ is the mass proportion of key equipment $j$ corresponding to order $i$.

For the general contractor, it is difficult to have a unique solution to deal with the local multi-objective optimization problem. By solving the above model, we can get the negotiation domain accepted by the general contractor: negotiation domain of delivery date $\left[D_{Z P}\right]$, price negotiation domain $\left[P_{Z P}\right]$ and quality negotiation domain $\left[Q_{Z P}\right]$. When the order-oriented revenue is optimal, the preference oriented optimal multi-issue negotiation result can be obtained. Delivery date $D_{Z P 1}^{*}$, price $P_{Z P 1}^{*}$, quality $Q_{Z P 1}^{*}$; similarly, when the completion rate is optimal and the quality is optimal, the corresponding negotiation results can be obtained: delivery date $D_{Z P 2}^{*} / D_{Z P 3}^{*}$, price $P_{Z P 2}^{*} / P_{Z P 3}^{*}$, and quality $Q_{Z P 2}^{*} / Q_{Z P 3}^{*}$. For any issue $\varphi \in\{D, P, Q\}$,

$$
\varphi_{Z P 1}^{*} \cap \varphi_{Z P 2}^{*} \cap \varphi_{Z P 3}^{*}=\varnothing
$$

It shows that there is no solution for the optimization result of preference-oriented issues, and it is necessary to negotiate and adjust the issues, so that the overall optimization effect of multiple issues is relatively good.

\subsubsection{SOA Decision-Making Model}

The local decision-making of shipowners for orders is more from the perspective of self-interest maximization, that is, smaller order cost and shorter delivery date. Similarly, the shipowner multi-objective optimization problem needs to be transformed into two single objective optimization problems, and the two single objective optimization problems need to be coordinated. The objective models of the two single objective optimization problems are: order price optimization model and delivery date optimization model.

(1) Order cost optimization model:

$$
Z C 1=\min \left\{P_{k}+\sum_{d} p_{k s}-f\left(d_{k}, f t_{k}\right)\right\}
$$

The constraints are:

$$
\begin{aligned}
& s t_{k} \geq r_{k} \\
& f t_{k} \leq \overline{d_{k}} \\
& q_{k j} \geq \overline{q_{k j}}
\end{aligned}
$$

(2) Delivery date optimization model:

$$
Z C 2=\min f t_{k}
$$


Among them, (14) represents the minimum objective function of the order cost of the shipowner, that is, the final order cost based on the negotiated contract price, delivery date and the price of directly purchased equipment, taking into account the delay penalty. Formula (15) shows that the order start time meets the release time constraint. Formula (16) indicates that the order completion time meets the delivery date constraint. Formula (17) indicates that all equipment in the order must meet the quality requirements. Formula (18) represents the objective function of the shortest delivery date of the order.

\subsubsection{SCA Decision-Making Model}

The local decision-making of strategic suppliers for orders is also considered from the maximization of their own interests, with profit maximization and production load balancing as the negotiation objectives. The objective models of two single objective optimization problems for strategic suppliers are profit maximization optimization model and production load balancing optimization model.

(1) Optimization model for profit maximization of strategic suppliers:

$$
Z S 1=\max \left\{p_{s} * \sum_{t \in I_{t}} r_{t}\left(q_{k j}\right) * c_{r}\right\}
$$

The constraints are:

$$
\begin{gathered}
s_{k s} \geq r_{k} \\
f_{k s} \leq \overline{d_{k}}-a a t_{k s} \\
\sum_{t \in I_{t}} r_{t}\left(q_{k j}\right) \leq \rho_{t}
\end{gathered}
$$

(2) The optimization model of production load balance for strategic suppliers:

$$
Z S 2=\min \sum_{t \in I_{t}}\left\{\left(\rho_{t}-\sum_{t \in I_{t}} r_{t}\right) / \rho_{t}\right\}^{2}
$$

The objective function (19) shows that the profit of production equipment is the largest. Formula (20) shows that the order release time constraint is satisfied. Formula (21) shows that the equipment delivery time constraint is met, $a a t_{k s}$ is the time requirement for the equipment to arrive in advance. Formula (22) shows that resource capacity constraints are met; $r_{t}\left(q_{k j}\right)$ indicates the unit resources to be consumed according to the quality standard $q_{k j}$. The objective function (23) represents the objective equilibrium of production load.

Similar to the multi-issue acceptance negotiation domain of the general contractor, there is also a corresponding multi-issue negotiation domain between the shipowner and the strategic supplier: negotiation domain of delivery date $\left[D_{Z C}\right] /\left[D_{Z S}\right]$, price negotiation domain $\left[P_{Z C}\right] /\left[P_{Z S}\right]$ and quality negotiation domain $\left[Q_{Z C}\right] /\left[Q_{Z S}\right]$. Obviously, for any issue $\varphi \in\{D, P, Q\}$,

$$
\varphi_{\mathrm{ZP}} \cap \varphi_{\mathrm{ZC}} \cap \varphi_{\mathrm{ZS}} \neq \varnothing
$$

Then, there is the possibility of negotiation between multi-agent, and the differences between them can be solved through multi-agent negotiation.

\subsection{Relaxed Optimization-Based Phased Negotiation Method}

By solving the local decision model proposed in Section 4.2, the acceptable negotiation domain of each agent can be obtained, that is, the optimal result of each agent's independent decision. On this basis, in order to achieve the goal of consensus negotiation in the Multi-Agent Coordination Decision Model, a multi-agent multi-issue phased negotiation mechanism based on Optimization relaxation is proposed. The negotiation process includes the following steps:

Step 1. Each Agent takes a single objective as the optimization objective to calculate its multi-issue optimal value and acceptable negotiation domain.

Step 2. Under the premise that the coordination agent judges that it is necessary (their optimal values are inconsistent) and possible (the public negotiation domain is not 
empty), the optimization relaxation is carried out. That is to say, the coordination agent puts forward concession suggestions according to the issue gap between each subject and concession strategy, and then each subject relaxes the optimization objectives and adjusts multiple issues.

When the result of each agent's local decision satisfies the Formula (24), that is, multiple agents have a common negotiation domain, the negotiation is carried out according to the following coordination decision model.

Define $D_{Z P}^{c}, P_{Z P}^{c}, Q_{Z P}^{c}$ as the expected delivery date, order price and equipment quality requirements of $G A ; D_{Z C}^{c}, P_{Z C}^{c}, Q_{Z C}^{c}$ are the expected delivery date, order price and equipment quality requirements of $S O A ; D_{Z S}^{c}, P_{Z S}^{c}, Q_{Z S}^{c}$ are the expected delivery date, order price and equipment quality of SCA. Because there is a public negotiation domain, it is possible to reach an agreement. A multi-agent coordination decision model is established:

$$
\begin{aligned}
\Delta D & =D_{\theta 1}^{c}-D_{\theta 2}^{c}=0, \theta 1 \& \theta 2 \in\{Z P, Z C, Z S\}, \theta 1 \neq \theta 2 \\
\Delta P & =P_{\theta 1}^{c}-P_{\theta 2}^{c}=0, \theta 1 \& \theta 2 \in\{Z P, Z C, Z S\}, \theta 1 \neq \theta 2 \\
\Delta Q & =Q_{\theta 1}^{c}-Q_{\theta 2}^{c}=0, \theta 1 \& \theta 2 \in\{Z P, Z C, Z S\}, \theta 1 \neq \theta 2
\end{aligned}
$$

s.t.

$$
\varphi_{\theta}^{c} \in\left[\varphi_{\theta}\right], \forall \varphi \in\{D, P, Q\}, \forall \theta \in\{Z P, Z C, Z S\}
$$

Target (25) means that any two parties agree on the delivery date, (26) indicates that any two parties have reached an agreement on the price issue, (27) indicates that any two parties reach an agreement on quality issues and the constraint condition (28) is that the negotiation results are within the acceptable negotiation domain of each decision-maker.

Step 3. Iterative negotiation, until each agent reaches an agreement on the negotiation result of multiple issues, the negotiation is successful and the decision result is output. Otherwise, the negotiation fails and the order is not accepted.

In the process of multi-agent multi-issue phased negotiation, the two key links are how to make concessions in the case of inconsistent issues, and how to adjust the constrained multi-issues within the decision-making body. It is necessary to study the corresponding concession strategy and issue adjustment strategy.

\subsubsection{Joint Concession Strategy Based on Majority}

Concession in the process of negotiation refers to that the agent actively sacrifices the interests of some issues or reduces expectations in the process of proposal and counter proposal, to bring two or more parties to an agreement. The design of concession strategy is an important part of agent negotiation. In order to shorten the negotiation gap and complete the negotiation as much as possible, concession strategies are designed according to the negotiation gap between decision-makers.

The order decision-making of complex shipbuilding project has the characteristics of multi-agent distributed cooperation, so the traditional forward and backward concession method cannot be used directly to design compromise strategy. The cooperative relationship of participants includes competition and cooperation. Table 1 describes four kinds of cooperation/competition relations of multi-agent cooperation in the collaborative decision-making process of complex shipbuilding project order. In the figure, " + " indicates that there is a cooperative relationship between the two, and "-" indicates that there is a competitive relationship.

Among them: (1) Indicate that they all cooperate with each other and have the same expectations for the issue, so there is no need for consultation. (4) Indicate that the relationship between the three parties is competitive, and the adjustment of the same issue cannot satisfy the three parties, so there is no room for negotiation; (2) and (3) there are differences between the majority and the minority, which can reduce the dimension of collaborative relationship through competition and cooperation, providing the possibility for negotiation. In an order collaborative decision-making problem of complex shipbuilding 
project, price issue and time issue belong to collaborative relationship (3), forming a negotiation situation of "shipowner, general contractor + supplier"; Quality issues belong to collaborative relationship (2), forming a negotiation situation of "Shipowner + general contractor supplier".

Table 1. Cooperative relationship between agents.

\begin{tabular}{cccc}
\hline Relationship & Agent 1-Agent 2 & Agent 1-Agent 3 & Agent 2-Agent 3 \\
\hline$(1)$ & + & + & + \\
\hline$(2)$ & + & + & - \\
\hline$(3)$ & + & - & - \\
\hline$(4)$ & - & - & - \\
\hline
\end{tabular}

Aiming at the two kinds of collaborative relationship in order decision-making of complex shipbuilding project, this paper puts forward the joint concession strategy of the majority party, which takes "multi win" as the negotiation goal, that is, it cannot increase the interests of a single party while damaging the interests of any party. Under the guidance of this goal, the majority joint concession strategy is designed, which can be divided into two kinds of different competition/cooperation relations: the partner's joint concession strategy in the same direction and the competitor's joint concession strategy in different directions.

For collaborative relationship (2), if the two parties with competitive relationship make joint concessions, for example, the negotiation goal (equipment quality) is in the middle range of the expected value of both parties, then the two competitive parties must be close to the negotiation goal (the general contractor reduces the quality requirements and the supplier improves the equipment quality), that is, to adjust the issue value in a different direction.

For the cooperative relationship (3), the two cooperative subjects share the change of benefits brought by concession. For example, if the negotiation target (order price) requires the partner to make 20 concessions, both parties (general contractor and supplier) must jointly undertake 20 price adjustments to reduce their own order revenue, that is, to adjust the issue value in the same direction.

This kind of joint concession strategy can obtain more win-win negotiation results in the process of iterative negotiation concession by the way that the majority bears more concession costs.

\subsubsection{Preference Oriented Issue Adjustment Strategy}

In order to solve the adjustment problem of multiple constrained issues within decision-makers, a preference oriented multi-issue adjustment strategy is designed. Decision makers' response to issue $T_{i}$ preference is $\omega_{i}$, the current issue value is $d_{i}$. The negotiation goal of this round of issues calculated by the joint concession strategy is $d_{i}^{*}$, the decision-maker can according to preference, negotiation gap $\Delta \mathrm{d}_{i}=d_{i}^{*}-d_{i}$ and iteration factor of issue adjustment $\varepsilon$ calculate the adjustment step of the current round:

$$
\mathrm{s}_{i}=f\left(\omega_{i}, \Delta d_{i}, \varepsilon\right)
$$

According to the operation mechanism of each agent in Section 4.1, calculate the corresponding issue adjustment step $\mathrm{s}_{i}$. Through the adjustment of multiple issues, the preferred issues in the iterative process of joint concession are adjusted less, and the multiple issues gradually converge.

Utility function is mainly used to evaluate the quality of negotiation. For each negotiation issue $T_{i}$, the decision-maker $A^{p} / A^{c} / A^{s}$ gives the corresponding expected value 
$v_{i}^{p} / v_{i}^{c} / v_{i}^{s}$, based on the concession principle, the negotiation target value $v_{i}$ should be in the range of $\left[v_{\min }, v_{\max }\right]$ :

$$
\begin{aligned}
& v_{\min }=\min \left\{v_{i}^{p}, v_{i}^{c}, v_{i}^{s}\right\} \\
& v_{\max }=\max \left\{v_{i}^{p}, v_{i}^{c}, v_{i}^{s}\right\}
\end{aligned}
$$

In order to achieve consensus, the intermediate value $v_{\text {mid }}=\left(v_{i}^{p}+v_{i}^{c}+v_{i}^{s}\right) / 3$ should be the target value of negotiation, that is, for decision-makers, when the issue $T_{i}$ value is $v_{\text {mid }}$, it means the value is moderate. However, the general decision-makers have a preference for the negotiation issues. When the decision-maker has a preference for the issue and the value is positive, it is considered that the value of $T_{i}$ is greater than $v_{\text {mid }}$, that is, the larger the value, the better. On the contrary, it is better when it is less than $v_{\text {mid }}$. The negotiation process of preference-oriented issue adjustment strategy is as follows:

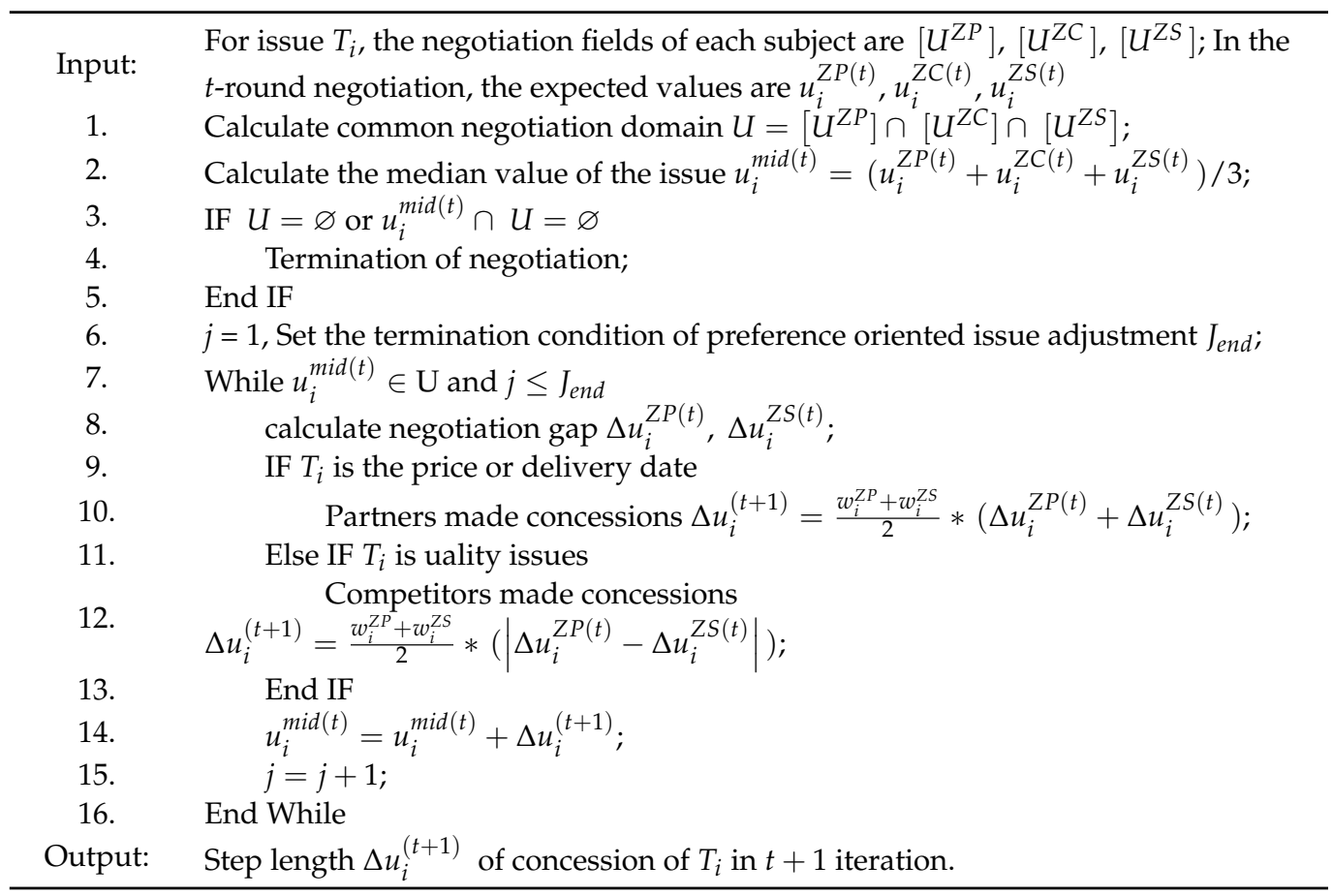

\subsubsection{Expected Revenue Strategy of Maximum Potential Order}

For the general contractor, the decision of order is also the planning and optimization of its own manufacturing capacity. In the planning cycle $\mathrm{T}$ of an enterprise, the decision of every stage $k$ needs to be an optimization decision, so as to achieve the goal of optimization in the whole decision-making process, this is a typical stochastic dynamic programming problem. The capability state of the enterprise at the beginning of phase $k$ is $x_{k}$, and the state transition function is set $\varphi$, calculate the state at the end of phase $k$ is $x_{k+1}=\varphi\left(x_{k}-a_{k}^{j}\right)$, the decision goal of stage $k$ is to maximize the revenue after accepting order $k$, which includes the revenue generated by completing order $k$ and the impact on subsequent orders after accepting order $k$.

In stochastic dynamic programming, the following objectives are solved recursively:

$$
f_{k}\left(x_{k}\right)=\left\{\begin{array}{c}
\max _{A_{k}}\left\{g_{k}\left(a_{k}^{j}\right)+E\left[f_{k+1}\left(x_{k+1}\right)\right]\right\}, k \neq n \\
\max _{A_{k}} g_{k}\left(a_{k}^{j}\right), k=n
\end{array}\right.
$$

Among them, $g_{k}\left(a_{k}^{j}\right)$ represents the revenue generated by the developed project plan $a_{k}^{j}$. If the order is not accepted, set $j=0$, then $g_{k}=0$, no profit; otherwise, $g_{k}=P_{k}-R_{k}^{j}-C_{k}^{j}-p_{k S}^{j}$, Where $P_{k}$ is the maximum order revenue, $R_{k}^{j}$ is the delay penalty, 
$C_{k}^{j}$ is the resource cost, and $p_{k S}^{j}$ is the purchase price of key equipment; $E\left[f_{k+1}\left(x_{k+1}\right)\right]$ is the influence of order $k$ decision on subsequent orders. Comparing task completion scheme $a_{k}^{j}$ and $a_{k}^{s}$, the selection of scheme A should meet the following principles $a_{k}^{j}$ :

$$
\left\{\begin{aligned}
g_{k}\left(a_{k}^{j}\right)+E\left[f_{k+1}\left(x_{k}-a_{k}^{j}\right)\right] & >g_{k}\left(a_{k}^{s}\right)+E\left[f_{k+1}\left(x_{k}-a_{k}^{s}\right)\right], k \neq n \\
g_{k}\left(a_{k}^{j}\right) & >g_{k}\left(a_{k}^{s}\right), k=n
\end{aligned}\right.
$$

Although stochastic dynamic programming (SDP) can solve the order decision-making problem in theory, it is difficult to get a satisfactory solution in acceptable time due to the high complexity and uncertainty of the problem in practice.

Based on stochastic dynamic programming model, this paper proposes a heuristic strategy: maximum potential order expected revenue strategy. If the probability of potential orders at time $t_{1}$ is greater than that at time $t_{2}$, that is, $\operatorname{Pr}\left[t_{1}\right]>\operatorname{Pr}\left[t_{2}\right]$ the current candidate order $k$ will be arranged after $t_{2}$ as far as possible, and the resources after $t_{1}$ will be reserved for potential orders. Decision makers need to make a trade-off between the current candidate orders and the future potential orders, and seek the result of greater revenue under the condition of limited capacity through probability estimation.

\section{Experiment and Results Analysis}

The proposed approach is implemented in a simulated manufacturing system. Simulations were performed on several Windows 10 operating systems with an Intel Core i7-6700 $2.60 \mathrm{GHz}$ processor and $8 \mathrm{~GB}$ of RAM to test the process of shipbuilding project order collaborative decision making. Agent behaviors and protocols were coded and collectively used to support the agent-based simulations.

In order to verify the solution effect of the proposed method, an illustrative example is conducted combining with the actual order data including 12 groups of test cases as shown in Table 2.

Table 2. Test example parameter setting and description.

\begin{tabular}{cccc}
\hline Code & Order Quantity & Tardiness Limit & Potential Order Probability \\
\hline 1 & 3 & $10 \%$ & 0.25 \\
2 & 3 & $10 \%$ & 0.5 \\
3 & 3 & $10 \%$ & 0.75 \\
4 & 3 & $20 \%$ & 0.25 \\
5 & 3 & $20 \%$ & 0.5 \\
6 & 3 & $20 \%$ & 0.75 \\
7 & 6 & $10 \%$ & 0.25 \\
8 & 6 & $10 \%$ & 0.5 \\
9 & 6 & $10 \%$ & 0.75 \\
10 & 6 & $20 \%$ & 0.25 \\
11 & 6 & $20 \%$ & 0.5 \\
12 & 6 & $20 \%$ & 0.75 \\
\hline
\end{tabular}

(1) Based on the enterprise research, combined with the actual influencing factors and expert opinions of the order decision-making of high-end ship development project, the preference weights of delivery date $\mathrm{D}$, order price $\mathrm{P}$ and product quality $\mathrm{Q}$ are set. The preference of general contractor is $0.3,0.5$ and 0.2 , that of ship owner is $0.3,0.4$ and 0.3 , and that of strategic supplier is $0.2,0.6$ and 0.2 .

(2) Considering the probability of potential orders, there will be orders with small probability, and the probability is 0.25 ; there may be an order, the probability is 0.5 , the probability will have an order, the probability is 0.75 .

(3) Two cases of ship type products are set up, including three orders and six orders, respectively, to verify the decision-making effect of the proposed method under different order sizes. 
(4) Set the project delay limit of $10 \%$ and $20 \%$, and verify the decision-making effect of the proposed method under different levels of requirements.

Around the orders in 12 groups of cases, the acceptable negotiation domains of ship delivery date, order price, product quality and other issues corresponding to shipowners, general contractors and strategic suppliers are set. The integer programming is used to optimize the optimization problem of each subject to obtain the results of local decisionmaking. If the values of all topics are consistent and in their respective negotiation domain, it is considered that the multi-agent win-win satisfactory solution is obtained. If not, negotiation is carried out until two or three parties reach agreement.

In order to verify the optimization effect of the proposed multi-agent multi-issue negotiation method on 12 groups of test experiments, it is compared with the other two negotiation methods CPSC [56] (real-time decision-making for uncertain orders) and CEN [57] (decision-making for urgent orders), and a group of verification results is selected for detailed description, as shown in Table 3.

Compared with the verification results in Table 3, it can be found that the negotiation results of the proposed method for three orders are in the acceptable negotiation domain, which realizes the win-win negotiation results of multi-agent; however, the other two negotiation methods adopt the method of two parties' cooperation, which leads to the first and second orders not reaching the synergy effect. For the third order, the three methods all achieve the win-win result of multi-agent, but relatively speaking, the negotiation result of this method in specific issues is closer to the optimal value of each agent's local decision. In view of this case, we can draw a conclusion: this method achieves the consensus of three orders, and the negotiation result is closer to the optimal value of local decisionmaking issues. It can be seen that the proposed method has better optimization effect for the multi-agent distributed collaborative order collaborative decision-making problem, and can better meet the needs of practical application.

For multi-agent collaborative decision-making, when multi-agent reaches a consensus decision-making result in the face of multiple issues that is to achieve a win-win situation among the three parties and obtain a satisfactory solution to the problem. Table 4 lists all the experimental results, representing the satisfactory solutions of different methods for all groups of test cases. In 10 groups of experiments, the method in this paper has obtained satisfactory solutions in line with the tripartite win-win situation, while the other two methods are five groups and seven groups, respectively. It can be seen that the method proposed in this paper can obtain more satisfactory solutions for the multi-agent distributed collaborative order decision-making problem, and can better meet the needs of practical application.

The maximum gap between the process value of multi-agent negotiation and the optimal value of local decision represents the convergence performance of negotiation method. Taking an order negotiation process as an example, the convergence speed of different methods is compared, as shown in Figure 8. The smaller the maximum gap is, the closer the negotiation result is to the optimal value of local decision. From the comparison of the convergence rate of the three methods, we can see that the method in this paper achieves convergence effect after 90 iterations, and the maximum gap between the final negotiation result and the optimal value of local decision is $42.3 \%$. Compared with the other two algorithms, it has better convergence rate and effect (56.5\% and $61 \%)$. It shows that the proposed negotiation method can take into account the convergence speed and the goal of tripartite win-win. 
Table 3. Comparison of solution results.

\begin{tabular}{|c|c|c|c|c|c|c|c|c|c|c|}
\hline \multirow{3}{*}{ Order Number } & \multirow{3}{*}{ Decision Makers } & \multirow{3}{*}{$\begin{array}{c}\text { Discussion Topics } \\
D\end{array}$} & \multirow{3}{*}{$\begin{array}{c}\text { Negotiation Domain } \\
{[73,112]}\end{array}$} & \multirow{3}{*}{$\begin{array}{c}\text { Independent Decision-Making } \\
110\end{array}$} & \multicolumn{6}{|c|}{ Coordination Results } \\
\hline & & & & & \multicolumn{2}{|c|}{ CPSC } & \multicolumn{2}{|c|}{ CEN } & \multicolumn{2}{|c|}{ The Proposed Method } \\
\hline & & & & & 98 & $\sqrt{ }$ & 98 & $\sqrt{ }$ & 96 & $\sqrt{ }$ \\
\hline \multirow{8}{*}{1} & $A^{p}$ & $P$ & {$[25,30]$} & 28 & 31 & $\sqrt{ }$ & 28 & $\sqrt{ }$ & 27 & $\sqrt{ }$ \\
\hline & & $Q$ & {$[0.2,1]$} & 0.8 & 0.6 & $\sqrt{ }$ & 0.6 & $\sqrt{ }$ & 0.7 & $\sqrt{ }$ \\
\hline & & $\widetilde{D}$ & {$[67,87]$} & 90 & 98 & $\sqrt{ }$ & 98 & $\sqrt{ }$ & 96 & $\sqrt{ }$ \\
\hline & $A^{c}$ & $P$ & {$[21,34]$} & 25 & 31 & $\sqrt{ }$ & 27 & $x$ & 27 & $\sqrt{ }$ \\
\hline & & $Q$ & {$[0.3,1]$} & 0.7 & 0.6 & $\sqrt{ }$ & 0.6 & $\sqrt{ }$ & 0.7 & $\sqrt{ }$ \\
\hline & & $\vec{D}$ & {$[60,130]$} & 102 & 98 & $\sqrt{ }$ & 98 & $\sqrt{ }$ & 96 & $\sqrt{ }$ \\
\hline & $A^{s}$ & $P$ & {$[17,35]$} & 28 & 32 & $\times$ & 28 & $\sqrt{ }$ & 27 & $\sqrt{ }$ \\
\hline & & $Q$ & {$[0.1,1]$} & 0.5 & 0.6 & $\sqrt{ }$ & 0.6 & $\sqrt{ }$ & 0.7 & $\sqrt{ }$ \\
\hline \multirow{8}{*}{2} & & $D$ & {$[72,124]$} & 98 & 101 & $\sqrt{ }$ & 95 & $\sqrt{ }$ & 92 & $\sqrt{ }$ \\
\hline & $A^{p}$ & $P$ & {$[24,35]$} & 31 & 26 & $\sqrt{ }$ & 30 & $\sqrt{ }$ & 28 & $\sqrt{ }$ \\
\hline & & $Q$ & {$[0.2,1]$} & 0.7 & 0.5 & $\sqrt{ }$ & 0.5 & $\sqrt{ }$ & 0.5 & $\sqrt{ }$ \\
\hline & & $\widetilde{D}$ & {$[63,116]$} & 78 & 101 & $\sqrt{ }$ & 95 & $\sqrt{ }$ & 92 & $\sqrt{ }$ \\
\hline & $A^{c}$ & $P$ & {$[20,30]$} & 23 & 26 & $\sqrt{ }$ & 28 & $\times$ & 28 & $\sqrt{ }$ \\
\hline & & $Q$ & {$[0.1,1]$} & 0.6 & 0.5 & $\sqrt{ }$ & 0.5 & $\sqrt{ }$ & 0.5 & $\sqrt{ }$ \\
\hline & & $\widetilde{D}$ & {$[76,110]$} & 97 & 108 & $\times$ & 95 & $\sqrt{ }$ & 92 & $\sqrt{ }$ \\
\hline & & $Q$ & {$[0.1,1]$} & 0.3 & 0.5 & $\sqrt{ }$ & 0.5 & $\sqrt{ }$ & 0.5 & $\sqrt{ }$ \\
\hline \multirow{9}{*}{3} & & $D$ & {$[33,75]$} & 68 & 58 & $\sqrt{ }$ & 56 & $\sqrt{ }$ & 60 & $\sqrt{ }$ \\
\hline & $A^{p}$ & $P$ & {$[20,32]$} & 27 & 28 & $\sqrt{ }$ & 29 & $\sqrt{ }$ & 28 & $\sqrt{ }$ \\
\hline & & $Q$ & {$[0.1,1]$} & 0.7 & 0.4 & $\sqrt{ }$ & 0.4 & $\sqrt{ }$ & 0.4 & $\sqrt{ }$ \\
\hline & & $\widetilde{D}$ & {$[25,60]$} & 54 & 58 & $\sqrt{ }$ & 56 & $\sqrt{ }$ & 60 & $\sqrt{ }$ \\
\hline & $A^{c}$ & $P$ & {$[21,35]$} & 25 & 28 & $\sqrt{ }$ & 29 & $\sqrt{ }$ & 28 & $\sqrt{ }$ \\
\hline & & $Q$ & {$[0.2,1]$} & 0.6 & 0.4 & $\sqrt{ }$ & 0.4 & $\sqrt{ }$ & 0.4 & $\sqrt{ }$ \\
\hline & & $\stackrel{\sim}{D}$ & {$[32,57]$} & 62 & 58 & $\sqrt{ }$ & 56 & $\sqrt{ }$ & 60 & $\sqrt{ }$ \\
\hline & $A^{s}$ & $P$ & {$[20,35]$} & 32 & 28 & $\sqrt{ }$ & 29 & $\sqrt{ }$ & 28 & $\sqrt{ }$ \\
\hline & & $Q$ & {$[0.1,1]$} & 0.3 & 0.4 & $\sqrt{ }$ & 0.4 & $\sqrt{ }$ & 0.4 & $\sqrt{ }$ \\
\hline
\end{tabular}


Table 4. Statistics of the win-win result of the test examples.

\begin{tabular}{|c|c|c|c|c|c|c|}
\hline \multirow{2}{*}{ Code } & \multicolumn{2}{|c|}{ CPSC } & \multicolumn{2}{|c|}{ CPSC } & \multicolumn{2}{|c|}{ The Proposed Method } \\
\hline & Multi-Win & Consensus & Multi-Win & Consensus & Multi-Win & Consensus \\
\hline 1 & Yes & 3 orders & Yes & 3 orders & Yes & 3 orders \\
\hline 2 & Two benefits & 1 order & Two benefits & 2 orders & Yes & 3 orders \\
\hline 3 & Two benefits & 1 order & Two benefits & 2 orders & Yes & 3 orders \\
\hline 4 & Yes & 3 orders & Yes & 3 orders & Yes & 3 orders \\
\hline 5 & Two benefits & 1 order & Yes & 3 orders & Yes & 3 orders \\
\hline 6 & Two benefits & 2 orders & Two benefits & 1 order & Yes & 3 orders \\
\hline 7 & Yes & 6 orders & Yes & 6 orders & Yes & 6 orders \\
\hline 8 & Two benefits & 3 orders & Yes & 6 orders & Two benefits & 4 orders \\
\hline 9 & Two benefits & 5 orders & Two benefits & 3 orders & Yes & 6 orders \\
\hline 10 & Yes & 6 orders & Yes & 6 orders & Yes & 6 orders \\
\hline 11 & Yes & 6 orders & Yes & 6 orders & Two benefits & 5 orders \\
\hline 12 & Two benefits & 4 orders & Two benefits & 4 orders & Yes & 6 orders \\
\hline
\end{tabular}

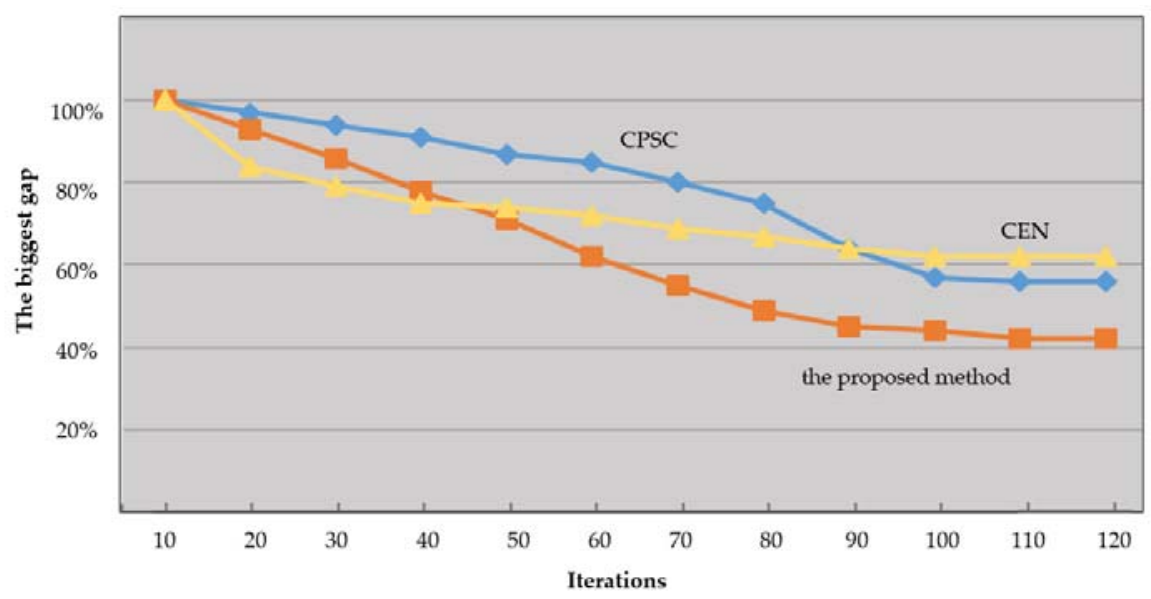

Figure 8. Convergence rate comparison of negotiation methods.

\section{An Application Case}

The prototype complex shipbuilding project collaborative order decision system (CSPCODS) is developed in the form of Java Web project using Java development language. The development technology framework adopts the lightweight Spring framework, which focuses on solving the complexity of enterprise application development. Screenshots of key functional interfaces in the prototype system are made, as shown in Figure 9.

Select five order data of the ship enterprise in a cycle. When the ship owner issues the order, the corresponding product technical parameters, release date, expected delivery date and other information are given. Based on the occupation of the dock, the key nodes corresponding to the order can be determined. Simulate the order collaborative decision-making process, invite the host supplier as a strategic supplier to participate in the order decision-making, and the latest arrival time of the host is 30 days before docking. Shipowners, shipyards and main engine suppliers negotiate on delivery date, order price, main engine delivery date/price/quality and other issues, so as to realize collaborative decision-making on orders. The proposed method is used to simulate the decision-making of five orders. Through collaborative decision-making, the shipping enterprises accepted four orders and made corresponding dock plans, as shown in Table 5.

For the demand of order decision-making of complex shipbuilding project, the system can realize the collaborative decision-making of orders based on part of the cooperation information of participating enterprises, and provide the project large node, order price, delivery time and quality of key equipment/task/technology package according to the 
scheduling demand. It changes the situation that the previous bidding is time-consuming and hard to meet the win-win demand, saves the negotiation cost, improves the efficiency of order decision-making and shortens the decision-making cycle by more than $30 \%$.

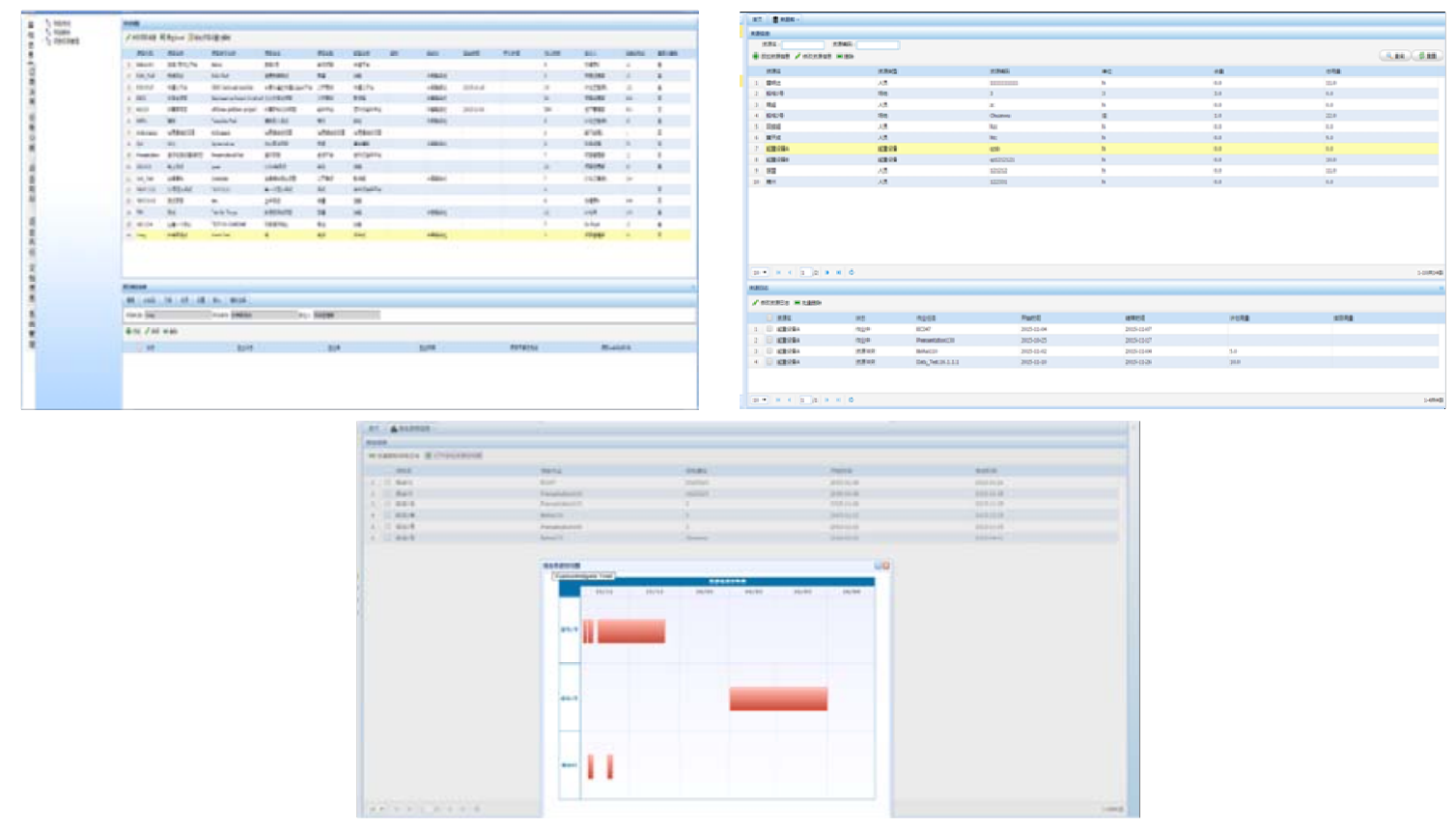

Figure 9. Collaborative order decision-making function interface.

Table 5. Large project nodes for order decision-making.

\begin{tabular}{cccccc}
\hline Project & Start & Sub-Production & Dock Carrying & Undocking & Delivery \\
\hline 1 & 20 July 2018 & 5 November 2018 & 25 February 2019 & 20 June 2019 & 1 August 2019 \\
2 & 10 March 2018 & 10 July 2018 & 5 November 2018 & 10 January 2019 & 10 March 2019 \\
4 & 20 April 2018 & 1 June 2018 & 1 August 2018 & 3 November 2018 & 10 February 2019 \\
5 & 10 August 2018 & 20 October 2018 & 11 January 2019 & 24 February 2019 & 30 March 2019 \\
\hline
\end{tabular}

\section{Conclusions}

In this paper, an assistant decision-making method is provided to support effective order collaborative decision-making for multi-wining negotiation results. The multi-agent multi-objective decision-making problem of ship owner, general contractor and strategic supplier is decomposed into multiple "single decision-making agent multi-objective optimization problem" and "multi decision-making agent negotiation problem". As a matter of fact, in many similar large-scale projects, there is no connection between order decision-making and production scheduling problems, which leads to inaccurate scheduling schemes and more frequent changes. The research in this paper provides a reference: the distributed and symmetric decision-making process can be effectively connected by parameterizing the local optimization and the cross-organizational coordination process.

From the perspective of engineering applications, an agent-based order collaborative decision-making framework was proposed, filling the research gap. The multi-agent winwin of order collaborative decision-making is effectively realized by designing a stage negotiation mechanism based on relaxation optimization, a joint concession strategy based on majority and a preference-oriented issue adjustment strategy. Case verification results show that the proposed negotiation method has a good optimization effect, 12 groups of cases get 10 groups of consensus results, and has relatively fast order decision-making speed. It changes the situation that the previous bidding is time-consuming and hard to meet the win-win demand, saves the negotiation cost, improves the efficiency of order 
decision-making and shortens the decision-making cycle by more than $30 \%$. From the academic perspective, this research contributes to the order collaborative decision-making problem solving for distributed large-scale complex engineering projects. Current and future work can be dedicated to expanding the system by designing more negotiation methods to deal with more possible engineering situations.

Author Contributions: X.M. designed the framework of complex shipbuilding project order collaborative decision-making and the negotiation method; J.L. proposed the symmetry characteristics of system and provided the method of system modeling; B.Y. provided the test data and environment to verify the proposed method and analyzed the test results; H.G. realized the concrete algorithm and developed the verification system. All authors have read and agreed to the published version of the manuscript.

Funding: This research was funded by the National Natural Science Foundation of China (No. 51679059), and “CNOOC intelligent manufacturing" (No. 2018473), and "Ministry of industry and information technology of high tech ocean going Passenger Ship Series" (No. 2019331).

Institutional Review Board Statement: Not applicable.

Informed Consent Statement: Not applicable.

Data Availability Statement: Not applicable.

Conflicts of Interest: The authors declared no potential conflict of interest with respect to the research, authorship, and/or publication of this article.

\section{References}

1. Zhang, A.N.; Ma, B.; Loke, D.; Kumar, S.; Chan, Y.Y. Multi-project planning and optimization for shipyard operations. In Proceedings of the IEEE International Conference on Industrial Engineering and Engineering Management, Hong Kong, China, 10-13 December 2012.

2. Hossain, K.A.; Golam Zakaria, N.M. A study on global shipbuilding growth, trend and future forecast. Procedia Eng. 2017, 194, 247-253. [CrossRef]

3. Gourdon, K. An analysis of market-distorting factors in shipbuilding: The role of government interventions. In OECD Science, Technology and Industry Policy Papers; OECD: Paris, France, 2019. [CrossRef]

4. Lee, Y.H.; Kumara, S.R.T.; Chatterjee, K. Multi-agent based dynamic resource scheduling for distributed multiple projects using a market mechanism. J. Intell. Manuf. 2003, 14, 471-484. [CrossRef]

5. Han, D.; Yang, B.; Li, J.; Wang, J.; Sun, M.; Zhou, Q. A multi-agent-based system for two-stage scheduling problem of offshore project. Adv. Mech. Eng. 2017, 9. [CrossRef]

6. Li, J.; Li, L.; Yang, B.; Zhou, Q. Development of a collaborative scheduling system of offshore platform project based on multi-agent technology. Adv. Mech. Eng. 2014, 298149. [CrossRef]

7. Järvenpää, E.; Lanz, M.; Siltala, N. Formal Resource and capability models supporting re-use of manufacturing resources. Procedia Eng. 2018, 19, 87-94. [CrossRef]

8. Thomas, A.; Singh, G.; Krishnamoorthy, M.; Venkateswaran, J. Distributed optimization method for multi-resource constrained scheduling in coal supply chains. Int. J. Prod. Res. 2013, 51, 2740-2759. [CrossRef]

9. Li, J.; Sun, M.; Han, D.; Yang, B.; Mao, X.; Zhou, Q. A governance platform for multi-project management in shipyards. Comput. Ind. Eng. 2018, 120, 179-191. [CrossRef]

10. Li, J.; Sun, M.; Han, D.; Wu, X.; Yang, B.; Mao, X.; Zhou, Q. Semantic multi-agent system to assist business integration: An application on supplier selection for shipbuilding yards. Comput. Ind. 2018, 96, 10-26. [CrossRef]

11. Li, J.; Sun, M.; Han, D.; Wang, J.; Mao, X.; Wu, X. A knowledge discovery and reuse method for time estimation in ship block manufacturing planning using DEA. Adv. Eng. Inform. 2019, 39, 25-40. [CrossRef]

12. Mao, X.; Li, J.; Guo, H.; Wu, X. Research on Collaborative Planning and Symmetric Scheduling for Parallel Shipbuilding Projects in the Open Distributed Manufacturing Environment. Symmetry 2020, 12, 161. [CrossRef]

13. Yang, B.; Geunes, J. A single resource scheduling problem with job-selection flexibility, tardiness costs and controllable processing times. Comput. Ind. Eng. 2007, 53, 420-432. [CrossRef]

14. Chen, Y.; Lu, Y.; Yang, G. Hybrid evolutionary algorithm with marriage of genetic algorithm and extremal optimization for production scheduling. Int. J. Adv. Manuf. Tech. 2008, 36, 959-968. [CrossRef]

15. Su, N.; Zhang, M.; Johnston, M.; Kay, C. Learning reusable Initial solutions for multi-objective order acceptance and scheduling problems with genetic programming. EuroGP 2013, 7831, 157-168.

16. Du, B.; Zhou, H. A robust optimization approach to the multiple allocation p-center facility location problem. Symmetry 2018, 10, 588. [CrossRef] 
17. Liu, L.; Su, J.; Zhao, B.; Wang, Q.; Chen, J.; Luo, Y. Towards an efficient privacy-preserving decision tree evaluation service in the Internet of Things. Symmetry 2020, 12, 103. [CrossRef]

18. Zeng, S.; Hussain, A.; Mahmood, T.; Ali, M.I.; Ashraf, S.; Munir, M. Covering-based spherical fuzzy rough set model hybrid with TOPSIS for multi-attribute decision-making. Symmetry 2019, 11, 547. [CrossRef]

19. Kucharska, E. Dynamic vehicle routing problem predictive and unexpected customer availability. Symmetry 2019, 11, 546.

20. Zavadskas, E.K.; Bausys, R.; Antucheviciene, J. Civil engineering and symmetry. Symmetry 2019, 11, 501. [CrossRef]

21. Jeong, H.; Cha, K.J. An ecient mapreduce-based parallel processing framework for user-based collaborative filtering. Symmetry 2019, 11, 748. [CrossRef]

22. Kim, B.; Byun, H.; Heo, Y.; Jeong, Y. Adaptive job load balancing scheme on mobile cloud computing with collaborative architecture. Symmetry 2017, 9, 65. [CrossRef]

23. Machuca, M.D.B.; Chinthammit, W.; Huang, W.; Wasinger, R.; Duh, H. Enabling symmetric collaboration in public spaces through 3D mobile interaction. Symmetry 2018, 10, 69.

24. $\mathrm{Wu}, \mathrm{Y}$.; He, F.; Han, S. Collaborative CAD synchronization based on a symmetric and consistent modeling procedure. Symmetry 2017, 9, 59. [CrossRef]

25. Dursun, M.; Arslan, Ö. An integrated decision framework for material selection procedure: A case study in a detergent manufacturer. Symmetry 2018, 10, 657. [CrossRef]

26. Yang, W.; Hu, Y.; Hu, C.; Yang, M. An agent-based simulation of deep foundation pit emergency evacuation modeling in the presence of collapse disaster. Symmetry 2018, 10, 581. [CrossRef]

27. Wang, L.; Lin, S. A multi-agent based agile manufacturing planning and control system. Comput. Ind. Eng. 2009, 57, 620-640. [CrossRef]

28. Reddy, R.H.; Kumar, S.K.; Fernandes, K.J.; Tiwari, M.K. A Multi-Agent System based simulation approach for planning procurement operations and scheduling with multiple cross-docks. Comput. Ind. Eng. 2017, 107, 289-300.

29. Miller, B.L. A Queuing Reward System with Several Customer Classes. Manag. Sci. 1969, 16, 234-245. [CrossRef]

30. Matsui, M. Job-shop Model: A production system with order selection. Int. J. Prod. Res. 1982, 20, 201-210. [CrossRef]

31. Matsui, M. Optimal order selection policies for a job-shop production system. Int. J. Prod. Res. 1985, 23, 23-31. [CrossRef]

32. Slotick, S.A.; Moton, T.E. Selecting jobs for a heavily loaded shop with lateens penalties. Comput. Oper. Res. 1996, 23, 131-140. [CrossRef]

33. Lewis, H.F.; Slotuick, S.A. Multi-period job selection: Planning work-loads to maximize pofit. Comput. Oper. Res. 2002, 28, 1081-1098. [CrossRef]

34. Baker, K.; Betrand, J. A dynamic priority rule for scheduling against due-dates. J. Oper. Manag. 1982, 3, 37-42. [CrossRef]

35. Betrand, J. The effect of workload dependent due-dates on job shop performance. Manag. Sci. 1983, 29, 799-816. [CrossRef]

36. Liao, C. Optimal control of jobs for production systems. Comput. Ind. Eng. 1992, 22, 163-169. [CrossRef]

37. Balakrishnan, J. The dynamics of plant layout. Manag. Sci. 2003, 39, 654-655. [CrossRef]

38. Keskinocak, P.; Ravi, R.; Tayur, S. Scheduling and Reliable Lead-Time Quotation for Orders with Availability Intervals and Lead-Time Sensitive Revenues. Manag. Sci. 2001, 47, 264-279. [CrossRef]

39. Susan, A.S.; Thomas, E.M. Order acceptance with weighted tardiness. Comput. Oper. Res. 2007, 34, 3029-3042.

40. Zhang, X.; Ma, S. Order Acceptance with limited capacity and finite output buffers in MTO environment. Ind. Eng. Manag. 2008, 2, 34-38.

41. Charnsirisakskul, K.; Griffin, P.M.; Keskinocak, P. Pricing and scheduling decisions with leadtime flexibility. Eur. J. Oper. Res. 2006, 171, 153-169. [CrossRef]

42. Song, S.J.; Wang, N.; Zhao, X.; Zhang, S. Order acceptance with limited capacity and finite output butters in BTO supply chain. J. Tianjin Polytech. Univ. 2013, 32, 84-88.

43. Ebben, M.; Hans, E.W.; Weghuis, F. Workload based order acceptance in job shop environments. OR Spectr. 2005, 27, 107-122. [CrossRef]

44. Xiao, Y.; Chang, W.; Zhang, R. A Research on Order Acceptance Model of Multi-line and Multi-stage. Ind. Eng. Manag. 2008, 6, 26-31.

45. Zhu, Y.; Pan, X.; Wang, Z. Delivery-data decision of electronic products orders for multiple assembly lines based on priority rule. Comput. Eng. Appl. 2010, 46, 10-12.

46. Wang, L.; Peng, J. Order acceptance method based on flexible due date in multi node environment. China Manag. Inform. 2012, 15, 45-47.

47. Fang, Y. Ant Colony Algorithms for Solving Order Acceptance and Scheduling; Nanjing University of Science and Technology: Nanjing, China, 2013.

48. Xie, X.; Wang, X. Lagrangian relaxation algorithm for order acceptance and scheduling in a single machine environment. J. Syst. Manag. 2020, 5, 874-881.

49. Yan, X. Research on Shop Scheduling Model of Order-Oriented Mixed Flow Production Line; North University of China: Taiyuan, China, 2020.

50. Shen, Z.; Tang, Q.; Huang, T.; Xiong, T. Solution of multistage flow shop scheduling model for leveling production. Comput. Integr. Manuf. Syst. 2019, 11, 2743-2752.

51. Zhu, Q.; Wang, X.; Geng, S. Decentralized decision-making problem of order acceptance and scheduling based on auction. Comput. Integr. Manuf. Syst. 2018, 24, 195-202.

52. Hao, J.; Yu, J.; Zhou, W. Order acceptance policy in Make-to-Order manufacturing based on average-reward reinforcement learning. J. Comput. Appl. 2013, 33, 976-979. [CrossRef] 
53. Fan, L.; Chen, X. Order Pricing and Acceptance policy in make-to-order firm based on revenue management. Syst. Eng. 2011, 29, 87-93.

54. Fei, H. Joint Scheduling of Production and Preventive Maintenance Integrating Due-Date Assignment in the Flow-Shop Problem under Uncertain Orders; Shanghai Jiao Tong University: Shanghai, China, 2017.

55. Wang, B.; Li, T.; Wang, H. Order acceptance and scheduling on parallel machines with setup time and machine-eligibility constraints. Chin. J. Eng. 2019, 41, 115-125.

56. Yoon, S.W.; Nof, S.Y. Cooperative production switchover coordination for the real-time order acceptance decision. Int. J. Prod. Res. 2011, 49, 1813-1826. [CrossRef]

57. Behdani, B.; Adhitya, A.; Lukszo, Z.; Srinivasan, R. Negotiation-based approach for order acceptance in a multiplant specialty chemical manufacturing enterprise. Ind. Eng. Chem. Res. 2011, 50, 5086-5098. [CrossRef] 